\title{
Piperine Is a Mechanism-Based Inactivator of CYP3A
}

\author{
Tiantian Cui, Qian Wang, Xiaoxiao Tian, Kehan Zhang, Ying Peng, ${ }^{1}$ and Jiang Zheng ${ }^{1}$ \\ State Key Laboratory of Functions and Applications of Medicinal Plants, Key Laboratory of Pharmaceutics of Guizhou Province, and \\ Key Laboratory of Environmental Pollution Monitoring and Disease Control, Ministry of Education, Guizhou Medical University, \\ Guiyang, P. R. China ${ }^{1}$ (J.Z.); Wuya College of Innovation, Shenyang Pharmaceutical University, Shenyang, Liaoning, P. R. \\ China $^{1}$ (T.C., Q.W., X.T., K.Z., Y.P., J.Z.)
}

Received August 7, 2019; accepted November 5, 2019

\begin{abstract}
Piperine (PPR) is the representative alkaloid component of the piper species (family: Piperaceae). Our rapid screening study found PPR caused time-dependent inhibition of cytochrome P450s (CYP) 3A and 2D6, and CYP3A was inactivated the most. Further study demonstrated that PPR is a time-, concentration-, and NADPHdependent inhibitor of CYP3A, and significant loss $(49.5 \% \pm 3.9 \%)$ of CYP3A activity was observed after 20minute incubations with $80 \mu \mathrm{M}$ PPR at $37^{\circ} \mathrm{C}$. The values of $K_{1}$ and $k_{\text {inact }}$ were $30.7 \mu \mathrm{M}$ and 0.041 minutes $^{-1}$, respectively. CYP3A competitive inhibitor ketoconazole showed protective effect against the enzyme inactivation. Superoxide dismutase/catalase and GSH displayed minor protection against the PPR-caused enzyme inactivation. Ferricyanide partially reduced the enzyme inhibition by PPR. Additionally, NADPH-dependent formation of reactive metabolites from PPR were found in human liver microsomal incubation mixtures. An ortho-quinone intermediate was trapped by NAC in
\end{abstract}

\section{Introduction}

Piperis fructus, nearly maturely or maturely dried fruits of Piper nigrum, are commonly used as dietary spices, such as food additives and condiments (Wattanathorn et al., 2008). Piperine (1-piperoylpiperidine, PPR) is a dominant alkaloid occurring in the fruits of long pepper (Piper longum Linn), black pepper (Piper nigrum Linn), and other piper species (family: Piperaceae) (Wattanathorn et al., 2008; Umar et al., 2013; Gupta et al., 2015). In addition, pepper has had a long history of medicinal use in Asian and Pacific islands (Bae et al., 2010; Umar et al., 2013). It is also often employed to treat diseases related to the gastrointestinal tract, particularly in Ayurvedic medicines (Johri and Zutshi, 1992; Gupta et al., 2015). PPR was reported to possesses multiple excellent and extensive pharmacological effects, such as anti-inflammatory (Bang et al., 2009; Murunikkara et al., 2012; Tasleem et al., 2014), analgesic (Tasleem et al., 2014), antioxidant (Chonpathompikunlert et al., 2010; Zarai et al., 2013; Samra et al., 2016), bioavailability enhancer

This work was supported in part by the National Natural Science Foundation of China [Grants 81830104, 81430086, 81773813, and U1812403]

${ }^{1}$ Y.P. and J.Z. contributed equally to this work. The two corresponding units contributed equally to this work.

https://doi.org/10.1124/dmd.119.088955.

S This article has supplemental material available at dmd.aspetjournals.org. microsomal incubations with PPR. DM-PPR, demethylene metabolite of PPR, showed weak enzyme inactivation relative to that caused by PPR. It appears that both carbene and orthoquinone intermediates were involved in the inactivation of CYP3A caused by PPR.

\section{SIGNIFICANCE STATEMENT}

CYP3A subfamily members (mainly CYP3A4 and CYP3A5) play a critical role in drug metabolism. Piperine (PPR), a methylenedioxyphenyl derivative combined with an unsaturated ketone, is the major active ingredient of pepper. PPR revealed time-, concentration-, and NADPH-dependent inhibitory effect on CYP3A. Carbene and quinone metabolites were both involved in the observed CYP3A inactivation by PPR. Apparently, the unsaturated ketone moiety did not participate in the enzyme inactivation. The present study sounds an alert of potential risk for food-drug interactions.

ABBREVIATIONS: DDQ, 2,3-dichloro-5,6-dicyano-1,4-benzoquinone; DM-PPR, demethylene piperine; EPI, enhanced product ion; GSH, glutathione; IS, internal standard; LC-MS/MS, liquid chromatography coupled to tandem mass spectrometry; MBI, mechanism-based inactivator; MDP, methylenedioxyphenyl; MRM, multiple reaction monitoring; NAC, N-acetylcysteine; P450, cytochrome P450; PBS, phosphate-buffered saline; PPR, piperine; ROS, reactive oxygen species; SOD, superoxide dismutase. 
containing such structures are microsomal substrates as well as inhibitors and have been documented to cause CYP inactivation. Alkaloids canadine, bulbocanine, and carnitine were reported to be mechanism-based and quasi-irreversible inactivators of CYP2C19 (Salminen et al., 2011). Myristicin is a mechanism-based inactivator of CYP1A2, and the reactive metabolites involved in the enzyme inactivation are quinone tautomers (Yang et al., 2015). Five kinds of MDP lignans found in piper cubeba were documented to be irreversible inhibitors of CYP3A4 reportedly resulting from their metabolic activation (Usia et al., 2005). Two reactive metabolites/intermediates derived from MDP-containing compounds are suggested to be responsible for the host enzyme inactivation, including catechol metabolites and carbene intermediates. The carbene intermediates can coordinate with the heme of CYP enzymes. The formation of carbeneheme-iron-porphyrin complexes results in quasi-irreversible inhibition of CYPs (Taxak et al., 2013). The catechols can be further oxidized to reactive ortho-quinones which sequentially alkylate apoprotein of CYPs (Hutzler et al., 2006, 2008).

Intake of foods may induce the expression or inhibit the activity of CYP enzymes, which may interfere with the pharmacokinetic properties of various drugs. For instance, grapefruit juice ingestion can specifically inhibit CYP3A4-mediated drug metabolism (Ohnishi et al., 2000). Furanocoumarin epoxybergamottin, a component squeezed from the peel of grapefruits into the juice during industrial manufacturing, was found to demonstrate inhibitory activity on CYP3A (Wangensteen et al.,
2003). CYP3A is the major P450 subfamily extensively distributed in hepatocytes and intestine epithelial cells (Rendic and Di Carlo, 1997; Murray, 2000).

In this study, we studied the inhibitory effect of PPR on human hepatic CYP enzymes and characterized the reactive metabolites possibly involved in enzyme inactivation. The significance of the present study is to understand the biochemical mechanism of the interaction of CYP enzymes with PPR, which is important to the justification of potential food-drug interactions resulting from PPR to ensure the safety and effectiveness of medications.

\section{Materials and Methods}

Chemicals. Piperine (PPR) with purity $>98 \%$ was acquired from Dalian Meilun Biotechnology Co., Ltd. (Dalian, China). Superoxide dismutase (SOD) was purchased from Shanghai Jianglai Biologic Technology Co., Ltd. (Shanghai, China). Propranolol, bupropion $\cdot \mathrm{HCl}$, dextromethorphan, tolbutamide, coumarin, testosterone, 4-nitrophenol, phenacetin, $\alpha$-naphthoflavone, pilocarpine, methoxsalen, sulfaphenazole, ticlopidine, quinidine, disulfiram, ketoconazole, NADPH, glutathione (GSH), $N$-acetylcysteine (NAC), and 2,3-dichloro-5,6-dicyano-1,4benzoquinone (DDQ) were obtained from Sigma-Aldrich (St. Louis, MO). Mixed human liver microsomes prepared from adult male donors and recombinant human CYP enzymes were provided by BD Gentest (Woburn, MA). All organic solvents and reagents were analytical or high-performance liquid chromatography

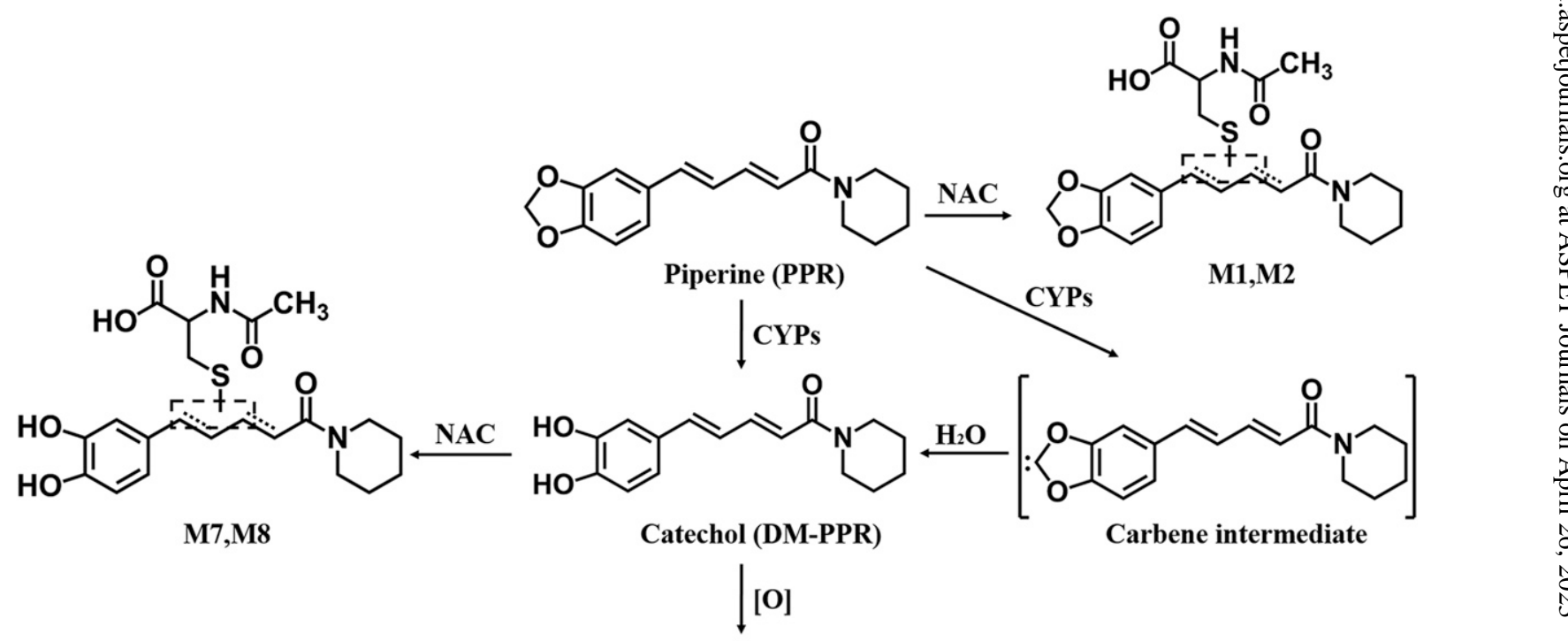

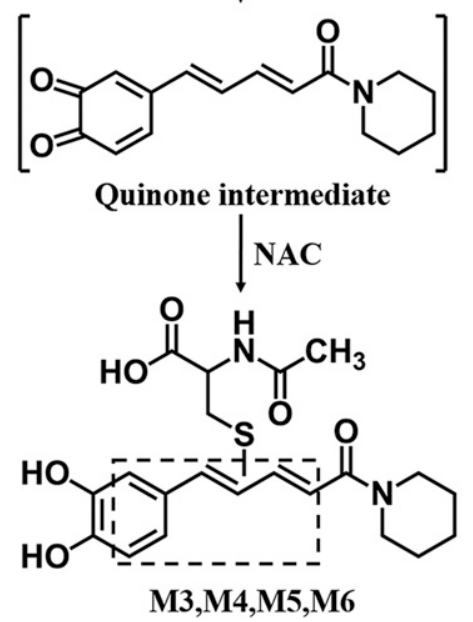

Scheme 1. Proposed pathways for the generation of reactive intermediate(s) and NAC conjugates derived from PPR. 

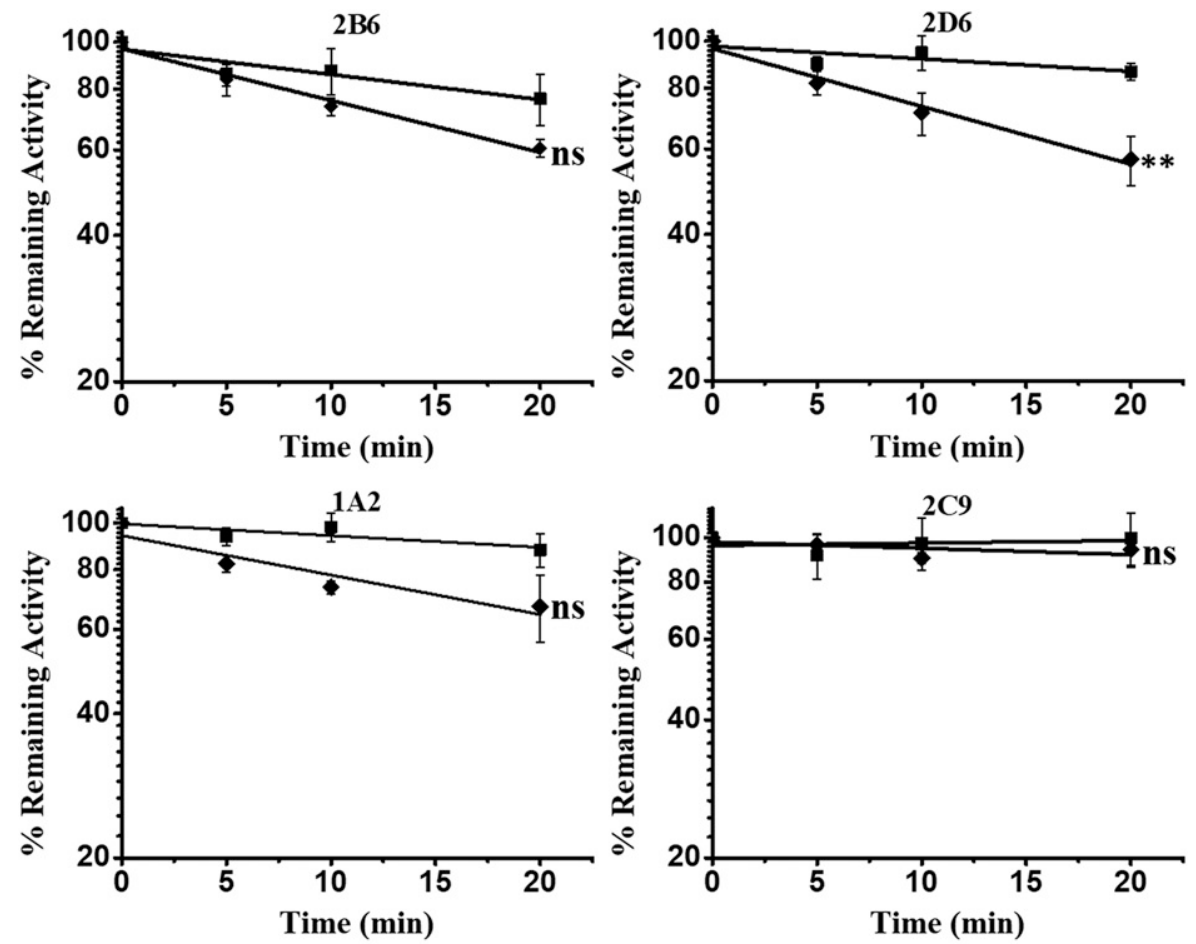

Fig. 1. Quick screening of time-dependent inhibition of cytochrome P450 enzymes by PPR. PPR at concentrations of $0(\mathbf{-})$ or $80(\downarrow) \mu \mathrm{M}$, human liver microsomes $(0.5 \mathrm{mg}$ protein $/ \mathrm{ml})$, and NADPH $(1.0$ $\mathrm{mM}$ ) were incubated at $37^{\circ} \mathrm{C}$ for $0,5,10$, and 20 minutes. The residual enzymatic activities at 0 minute were normalized to $100 \%$. Data represent the mean \pm S.D. $(n=3)$. Comparisons were made using an unpaired $t$ test. * indicates the significance of the remaining enzyme activity of experimental groups with respect to that of control at the same time point (20 minutes) of incubations. Levels are considered significant at $* P<0.05 ; * * P<0.01 ; * * * P<0.001 ; \mathrm{ns}$, not significant.
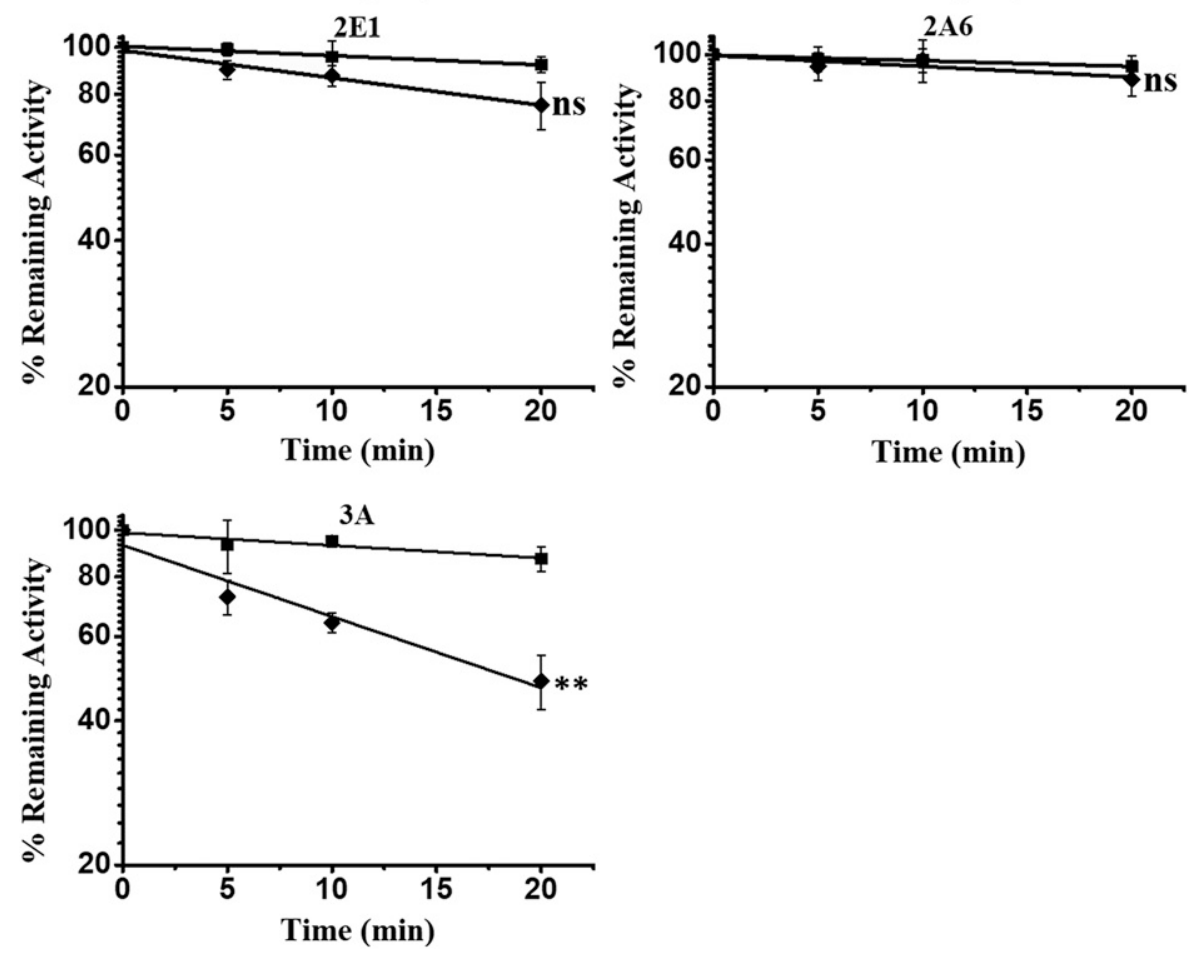

grade and purchased from Fisher Scientific (Springfield, NJ). DMSO- $d_{6}$ was purchased from Cambridge Isotope Laboratories, Inc. (Tewksbury, MA).

Chemical Synthesis of DM-PPR. PPR $(4.0 \mathrm{mg})$ and $8.0 \mathrm{mg}$ of anhydrous $\mathrm{AlCl}_{3}$ were placed in a $25 \mathrm{ml}$ round-bottom flask and mixed with $3.0 \mathrm{ml}$ of toluene. The mixture was then refluxed at $110^{\circ} \mathrm{C}$ for 12 hours, followed by incorporation of additional anhydrous $\mathrm{AlCl}_{3}(2.0 \mathrm{mg})$ and another 12 hours of refluxing. The resulting mixture was mixed with $0.5 \mathrm{ml}$ of water after being cooled to room temperature, and shaken well. The resulting mixture was concentrated under vacuum. The residue was submitted to semipreparative liquid chromatography for purification, and purified DM-PPR (Scheme 1) was characterized by mass spectrometry (MS) on Bruker hybrid quadrupole-time- of-flight mass spectrometer and NMR on a BRUKER-ARX-600 spectrometer (Bruker Corporation, Carteret, NJ).

Chemical Synthesis of NAC Conjugates. NAC conjugates M1 and M2 were synthesized as follows: PPR $(200 \mu \mathrm{M})$ was directly mixed with NAC $(20 \mathrm{mM})$ in phosphate-buffered saline (PBS) $(100 \mathrm{mM}, 2 \mathrm{ml})$, followed by stirring at $37^{\circ} \mathrm{C}$ for 60 minutes and centrifugation at $19,000 \mathrm{~g}$. The supernatants were analyzed by liquid chromatography coupled to tandem MS (LC-MS/MS). For synthesis of NAC conjugates M3-M8, DM-PPR $(1.0 \mathrm{mg}, 3.7 \mu \mathrm{mol})$ was dissolved in $2.0 \mathrm{ml}$ of $\mathrm{CH}_{2} \mathrm{Cl}_{2}$. After mixed with DDQ $(2.0 \mathrm{mg}, 8.8 \mu \mathrm{mol})$, the solution was stirred at $4^{\circ} \mathrm{C}$ for 4 hours. The organic solvent was removed by evaporation, and the resulting crude products were redissolved in $2.0 \mathrm{ml}$ of water. The mixture was 


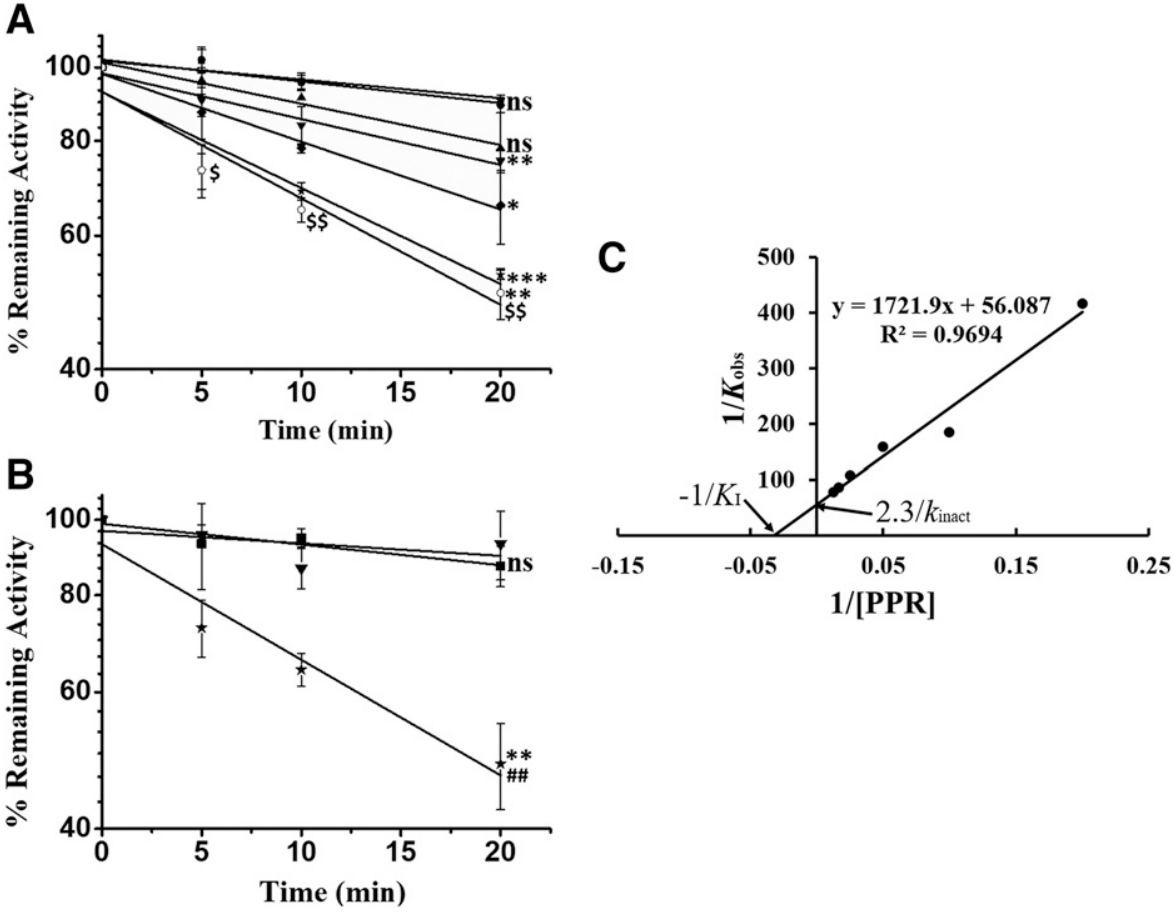

Fig. 2. (A) Time- and concentration-dependent inhibition of CYP3A by PPR. PPR at concentrations of $0(\bullet), 5(\bullet), 10(\boldsymbol{\Delta}), 20(\boldsymbol{\nabla}), 40(\diamond), 60(\star)$, and $80(\bigcirc)$ $\mu \mathrm{M}$ was incubated with human liver microsomes $(0.5 \mathrm{mg}$ protein $/ \mathrm{ml})$ fortified with NADPH $(1.0 \mathrm{mM})$ at $37^{\circ} \mathrm{C}$ for $0,5,10$, and 20 minutes. (B) NADPHdependent inactivation of CYP3A4 by PPR. Human liver microsomes $(0.5 \mathrm{mg} / \mathrm{ml})$ were incubated with vehicle $(\boldsymbol{\square})$ or PPR $(80 \mu \mathrm{M})$ in the absence $(\boldsymbol{\nabla})$ or presence $(\star)$ of NADPH. (C) Wilson's plot. $k_{\text {obs }}$ values were calculated from the slope of the regression lines shown in (A). Data represent the mean \pm S.D. $(n=3)$. * indicates the significance of the remaining enzyme activity of experimental groups with respect to that of control at the same time point (20 minutes) of incubations. ${ }^{\$}$ indicates the significance of the remaining enzyme activity of experimental groups at various incubation times, compared with that at 0 minute under the same incubation condition. ${ }^{\#}$ indicates the significance of the remaining enzyme activity in the presence of NADPH, compared with that in the absence of NADPH under the same incubation condition. Levels are considered significant at $* P<0.05 ; * * \$ \$ \$ \# \#<$ $0.01 ; * * * P<0.001 ;$ ns, not significant.

further reacted with NAC $(4.0 \mathrm{mg}, 25 \mu \mathrm{mol})$ with stirring at room temperature for 12 hours. The final mixture was centrifuged, and the supernatants $(5.0 \mu \mathrm{l})$ were subjected to LC-MS/MS for analysis.

Screening of Time-Dependent CYP Inhibition by PPR. The time-course inhibitory effects of PRR on CYPs were determined by monitoring individual CYP activities of human liver microsomes at various time points after being exposed to PPR. The primary incubation mixtures contained PPR $(0$ or $80 \mu \mathrm{M})$, $\mathrm{MgCl}_{2}(3.2 \mathrm{mM})$, and human liver microsomes $(0.5 \mathrm{mg}$ protein $/ \mathrm{ml})$ in $200 \mu \mathrm{l}$ PBS $(100 \mathrm{mM}, \mathrm{pH}=7.4)$. After preincubation at $37^{\circ} \mathrm{C}$ for 3 minutes, NADPH $(1.0$ $\mathrm{mM}$ ) was added to the primary incubations to initiate the reactions. After the primary mixtures were incubated for $0,5,10$, and 20 minutes, $40 \mu 1$ aliquots were transferred to the secondary reaction mixtures $(120 \mu \mathrm{l})$ composed of individual probe substrates (100 $\mu \mathrm{M}$ bupropion for CYP2B6, $50 \mu \mathrm{M}$ phenacetin for CYP1A2, $5.0 \mu \mathrm{M}$ dextromethorphan for CYP2D6, $120 \mu \mathrm{M}$ tolbutamide for CYP2C9, $200 \mu \mathrm{M}$ 4-nitrophenol for CYP2E1, $200 \mu \mathrm{M}$ coumarin for CYP2A6, or $200 \mu \mathrm{M}$ testosterone for CYP3A), $\mathrm{MgCl}_{2}(3.2 \mathrm{mM})$, and $\mathrm{NADPH}(1.0 \mathrm{mM})$, and further incubation for 15 minutes, respectively. Ice-cold acetonitrile $(120 \mu \mathrm{l})$ containing internal standard (IS) propranolol $(100 \mathrm{ng} / \mathrm{ml})$ was mixed with the incubation solution to quench the reactions. The resulting supernatants after vortex-mixing and centrifuging were analyzed by LC-MS/MS. The loss of enzyme activities was determined by monitoring the generation of the metabolites resulting from the probe substrates applied in the secondary incubations.

Determination of Time-, Concentration-, and NADPH-Dependent Inhibition of CYP3A. The primary incubation mixtures ( $200 \mu \mathrm{l})$ were composed of PPR at concentrations of $0,5.0,10,20,40,60$, or $80 \mu \mathrm{M}, \mathrm{MgCl}_{2}(3.2 \mathrm{mM})$, and human liver microsomes $(0.5 \mathrm{mg}$ protein/ml) in PBS (100 mM, pH 7.4). After 3 minute preincubation, the reaction was initiated by the addition of NADPH $(1.0 \mathrm{mM})$. At time points of $0,5,10$, and 20 minutes, $40 \mu \mathrm{l}$ of the primary incubations was withdrawn for CYP3A activity assessment in the secondary incubations that contained testosterone $(200 \mu \mathrm{M})$ and NADPH $(1.0 \mathrm{mM})$ in PBS $(100 \mathrm{mM}, \mathrm{pH} 7.4)$. After a 15 minutes incubation, the reactions were quenched using ice-cold acetonitrile $(120 \mu \mathrm{l})$ containing propranolol $(100 \mathrm{ng} / \mathrm{ml})$ as IS. The supernatants were analyzed by LC-MS/MS after being centrifuged at 19,000 $g$ for 10 minutes. To determine NADPHdependence of the observed CYP3A enzyme inhibition, PBS, which replaced NADPH with the same volume was included in microsomal incubations with PPR $(80 \mu \mathrm{M})$.

Determination of Time- and NADPH-Dependent Inhibition of CYP3A by DM-PPR. The inhibitory effect of DM-PPR on CYP3A was evaluated, and similar protocol as above was executed except for the replacement of PPR with DM-PPR $(80 \mu \mathrm{M})$. Control incubations lacked DM-PPR or NADPH.
Determination of Effect of Ketoconazole on PPR-Mediated Inactivation of CYP3A. Ketoconazole is a competitive inhibitor of CYP3A. The primary incubation system contained PPR $(80 \mu \mathrm{M}), \mathrm{MgCl}_{2}(3.2 \mathrm{mM})$, human liver microsomes $(0.5 \mathrm{mg}$ protein $/ \mathrm{ml})$, and ketoconazole at concentrations of $0,0.01$, 0.1 , and $1.0 \mu \mathrm{M}$. The procedures of subsequent reaction initiation/termination and sample preparation were the same as described above.

Determination of Effects of SOD/Catalase and GSH on PPR-Mediated Inactivation of CYP3A. Nucleophile glutathione (GSH, $2.0 \mathrm{mM}$ ) was included in the primary mixture together with PPR $(80 \mu \mathrm{M}), \mathrm{MgCl}_{2}(3.2 \mathrm{mM})$, human liver microsomes $(0.5 \mathrm{mg}$ protein $/ \mathrm{ml})$, and NADPH $(1.0 \mathrm{mM})$. At 0 and 20 minutes, the resulting incubation mixtures ( $40 \mu \mathrm{l}$ for each) were transferred to the secondary incubations containing probe substrate testosterone for the evaluation of the remaining enzyme activities. In a separate study, similar incubations were performed except incorporation of superoxide dismutase (SOD) and catalase (800 unit $/ \mathrm{ml}$ for each) to replace GSH. The control groups lacked either GSH or SOD/catalase.

Determination of Partition Ratio. To determine the partition ratio, PPR at final concentrations of $0,2.0,5.0,10,20,40,60,80$, and $100 \mu \mathrm{M}$ and human

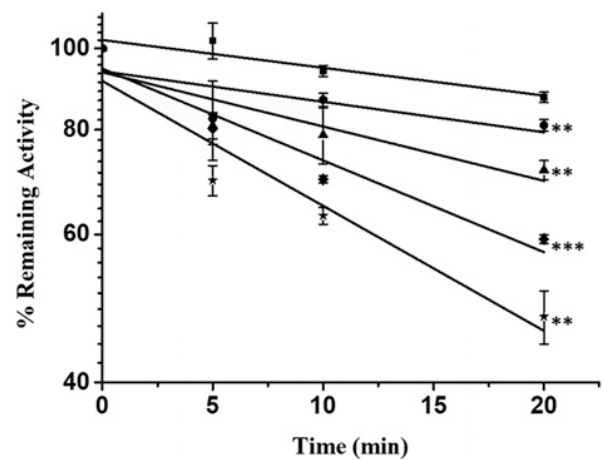

Fig. 3. Effect of competitive inhibitor on inactivation of CYP3A by PPR. Human liver microsomes $(0.5 \mathrm{mg}$ protein/ml) were incubated with vehicle $(\mathbf{\square})$ or PPR $(80 \mu \mathrm{M})$ supplemented with ketoconazole at concentrations of $0(\star), 0.01(\diamond), 0.1$ $(\boldsymbol{\Lambda})$, or $1.0(-\mu \mathrm{M}$. Data represent the mean \pm S.D. $(n=3) . *$ indicates the significance of the remaining enzyme activity of experimental groups with respect to that of control at the same time point (20 minutes) of incubations. Levels are considered significant at $* P<0.05 ; * * P<0.01 ; * * * P<0.001$ 


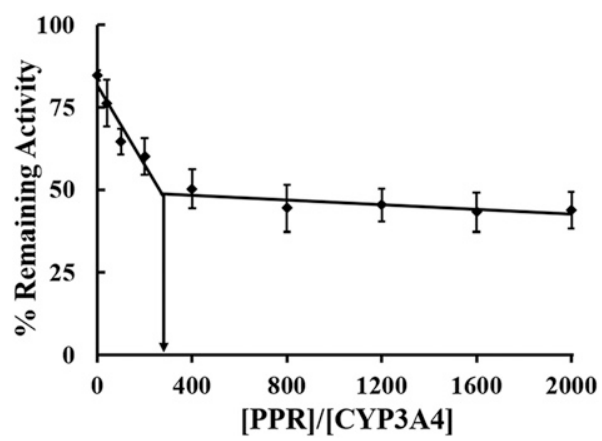

Fig. 4. Partition ratio of CYP3A4 inactivation by PPR. CYP3A4 $(50 \mathrm{nM})$ was incubated with PPR at designed concentrations $(0,2,5,10,20,40,60,80$, or $100 \mu \mathrm{M})$. The extrapolated $P+1$ value was determined from the point of intersection to the abscissa. Data represent the mean \pm S.D. $(n=3)$.

recombinant CYP3A4 (50 nM) were mixed in the primary reactions. NADPH $(1.0 \mathrm{mM})$ was added to initiate the reactions. Aliquots $(40 \mu \mathrm{l})$ were taken at time points of 0 and 20 minutes to the secondary incubation mixtures containing testosterone as a probe substrate for measuring the remaining CYP3A4 activities.

Determination of Reversibility of PPR-Mediated CYP3A Inhibition through Dialysis. A mixture of PPR $(0$ or $80 \mu \mathrm{M})$, human liver microsomes $(0.5 \mathrm{mg}$ protein $/ \mathrm{ml})$, and NADPH $(1.0 \mathrm{mM})$ was incubated at $37^{\circ} \mathrm{C}$ for 0 and 20 minutes. The resulting mixture was transferred into Slide-A-Lyzer cassettes (molecular mass cutoff: $3500 \mathrm{Da}$; Pierce, Rockford, IL) and dialyzed in $900 \mathrm{ml}$ of PBS (100 mM, pH 7.4) at $4^{\circ} \mathrm{C}$ three times for 2 hours each time. In parallel, nondialyzed samples were allowed to stand at $4^{\circ} \mathrm{C}$ for 6 hours. Aliquots $(40 \mu \mathrm{l})$ of all samples were submitted to the secondary incubations (120 $\mu \mathrm{l})$ composed of testosterone as a probe substrate after being brought to room temperature, respectively. CYP3A enzyme activities of the resulting mixtures were determined as stated below.

Determination of Reversibility of PPR-Mediated CYP3A Inhibition by Potassium Ferricyanide. Whether carbene intermediate was involved in PPRmediated CYP3A inhibition was determined by following the reported methods (Watanabe et al., 2007; Hong et al., 2015). Briefly, the primary incubations containing PPR $(0$ or $80 \mu \mathrm{M})$, human liver microsomes $(0.5 \mathrm{mg} / \mathrm{ml})$, and NADPH were executed at $37^{\circ} \mathrm{C}$. After 0 or 20 minutes incubation, the resulting solutions $(40 \mu \mathrm{l})$ were mixed with $\mathrm{K}_{3} \mathrm{Fe}(\mathrm{CN})_{6}(0$ or $2.0 \mathrm{mM})$ dissolved in $10 \mu \mathrm{l}$ of PBS (100 mM, pH 7.4). After 10 minutes incubation, the mixtures were subjected to secondary incubation for assessment of the remaining CYP3A activities as below.

P450 Enzyme Assays. The amounts of the products formed from individual probe substrates were measured to evaluate the corresponding CYP enzyme activities by an AB Sciex 5500 triple-quadrupole mass spectrometer (Applied Biosystems, Foster City, CA) equipped with an Agilent 1260 Series Rapid Resolution HPLC (Agilent Technologies, Santa Clara, CA). A Promosil $\mathrm{C}_{18}$ column $(150 \times 4.6 \mathrm{~mm}, 5 \mu \mathrm{m}$; Agela Technologies, Inc., Tianjin, China) was employed for analyte separation. The solvent system was composed of mobile phase A (water containing $0.1 \%$ formic acid) and phase B (acetonitrile with $0.1 \%$ formic acid). The flow rate was maintained at $0.8 \mathrm{ml} / \mathrm{min}$. The gradient elution was set as follows: 1) 0-2.0 minutes, 90\% A; $2.0-2.5$ minutes, 90\%-70\% A; 2.5-14.0 minutes, 70\%-30\% A; $14.0-14.1$ minutes, 30\%-10\% A; 14.1-15.0 minutes, $10 \%-90 \% \mathrm{~A} ; 15.0-17.0$ minutes, $90 \%$ A for the products of CYP2B6, 2D6, and 1A2; 2) 0-2.0 minutes, 90\% A; 2.0-5.0 minutes, 90\%-30\% A; $5.0-10.0$ minutes, $30 \%-5 \%$ A; $10.0-12.0$ minutes, $5 \%$ A; 12.0-13.0 minutes, $5 \%-90 \%$ A; $13.0-15.0$ minutes, $90 \%$ A for the products of CYPs2C9, 2E1, and 2A6; and 3) 0-3.0 minutes, 70\% A; 3.0-8.0 minutes, 70\%-66\% A; 8.0-10.0 minutes, 66\%-10\% A; 10.0-11.0 minutes, $10 \%$ A; 11.0-11.1 minutes, $10 \%-70 \% \mathrm{~A} ; 11.1-13.0$ minutes, $70 \% \mathrm{~A}$ for the product of CYP3A. Multiple reaction monitoring (MRM) scan mode was applied to quantitate the products. Ion pairs of MRM acquired included the following: $152.1 \rightarrow 110.0$ for acetaminophen (CYP1A2), $256.0 \rightarrow 238.0$ for hydroxybupropion (CYP2B6), 287.2 $\rightarrow 171.2$ for 4-hydroxytolbutamide (CYP2C9), 258.2 $\rightarrow 157.1$ for dextrorphan (CYP2D6), 305.3 $\rightarrow 269.4$ for $6 \beta$-hydroxytestosterone (CYP3A), and $260.3 \rightarrow 116.3$ for propranolol (IS) in positive mode, $161.0 \rightarrow 105.1$ for 7-hydroxycoumarin (CYP2A6), and $153.9 \rightarrow 122.8$ for 4-nitrocatechol (CYP2E1) in negative mode.
TABLE 1

Effects of $\mathrm{K}_{3} \mathrm{Fe}(\mathrm{CN})_{6}$ on the inactivation of CYP3A

Data represent the mean \pm S.D. $(n=3)$. The percentage of CYP3A activity was determined by calculation of the ratio of enzyme activity of each sample after 0 or 20 minute incubation with PPR vs. that of the corresponding control sample without PPR treatment. \% Reversed stands for the contribution of KFC to the recovered activity of CYP3A.

\begin{tabular}{lcc}
\hline \multirow{2}{*}{ System } & \multicolumn{2}{c}{ CYP3A } \\
\cline { 2 - 3 } & \% Control (0 min) & \% Control (20 min) \\
\hline - KFC & $50.7 \pm 2.9$ & $40.5 \pm 2.6$ \\
+ KFC & $86.3 \pm 8.4$ & $80.2 \pm 15.7$ \\
\% Reversed & $/$ & 39.7 \\
\hline
\end{tabular}

KFC, potassium ferricyanide.

Metabolite Identification. PPR $(100 \mu \mathrm{M})$, human liver microsomes $(1.0 \mathrm{mg}$ protein $/ \mathrm{ml}), \mathrm{MgCl}_{2}(3.2 \mathrm{mM}), \mathrm{NAC}(10 \mathrm{mM})$, and NADPH $(1.0 \mathrm{mM})$ were mixed in $100 \mu \mathrm{lPBS}(100 \mathrm{mM}, \mathrm{pH} 7.4)$ and incubated at $37^{\circ} \mathrm{C}$ for 30 minutes. NADPH was not included in negative control. The resulting reactions were processed as above, followed by LC-MS/MS analysis. The mobile-phase system included water (A) and acetonitrile (B), both containing $0.1 \%$ formic acid. And the column was eluted with a gradient program as follows: 0-2.0 minutes, $80 \% \mathrm{~A}$; 2.0-9.0 minutes, $80 \%-55 \%$ A; $9.0-13.0$ minutes, $55 \%$ A; $13.0-14.0$ minutes, 55\%-10\% A; $14.0-15.0$ minutes, $10 \%$ A; $15.0-16.0$ minutes, $10 \%-80 \%$ A; 16.0-18.0 minutes, $80 \%$ A. An AB SCIEX Instruments 4000 hybrid triple quadrupole-liner ion trap (Q-Trap) mass spectrometer was applied to characterize NAC conjugates. MS/MS analyses were executed through an MRM-EPI (enhanced product ion)scanning in positive-ion mode $(449.0 \rightarrow 320.0$ for M1 and M2, $435.0 \rightarrow 221.0$ for M3-M6, and $437.0 \rightarrow 181.1$ for M7 and M8).

Metabolizing Enzyme Inhibition Studies. To determine which P450 enzymes preferentially catalyze the metabolism of PPR, PPR was incubated with

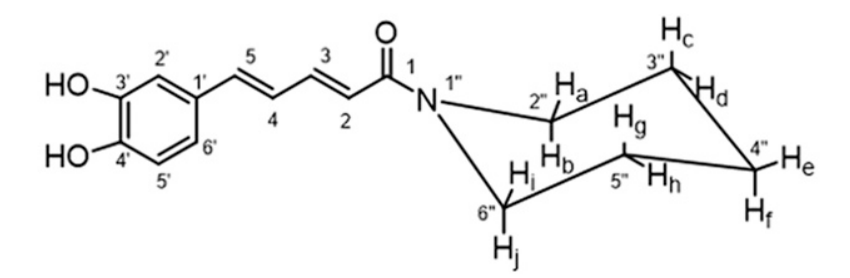

\begin{tabular}{rcc}
\hline Proton & Proton Chemical Shift(ppm) & $J(\mathrm{~Hz})$ \\
\hline HO-4' & $9.29(1 \mathrm{H}, \mathrm{s})$ & - \\
HO-3' & $9.05(1 \mathrm{H}, \mathrm{s})$ & - \\
H-3 & $7.22-7.18(1 \mathrm{H}, \mathrm{ddd})$ & $14.6,7.3,3.0$ \\
H-2' & $6.91(1 \mathrm{H}, \mathrm{d})$ & 2.0 \\
H-6' & $6.80-6.79(1 \mathrm{H}, \mathrm{dd})$ & $2.0,8.2$ \\
H-5 & $6.78(1 \mathrm{H}, \mathrm{d})$ & 4.3 \\
H-4 & $6.77(1 \mathrm{H}, \mathrm{s})$ & - \\
H-5' & $6.72-6.71(1 \mathrm{H}, \mathrm{d})$ & -1 \\
H-2 & $6.67-6.65(1 \mathrm{H}, \mathrm{d})$ & - \\
Ha, Hi & $3.52(2 \mathrm{H}, \mathrm{s})$ & - \\
Hb, Hj & or & - \\
He, Hf & $1.61-1.57(2 \mathrm{H}, \mathrm{m})$ & - \\
Hc, Hg & $1.49(2 \mathrm{H}, \mathrm{s})$ & or \\
Hd, Hh & $1.45(2 \mathrm{H}, \mathrm{s})$ & - \\
\hline
\end{tabular}

Fig. 5. Chemical structure and ${ }^{1} \mathrm{H}$ NMR chemical shifts of DM-PPR. 

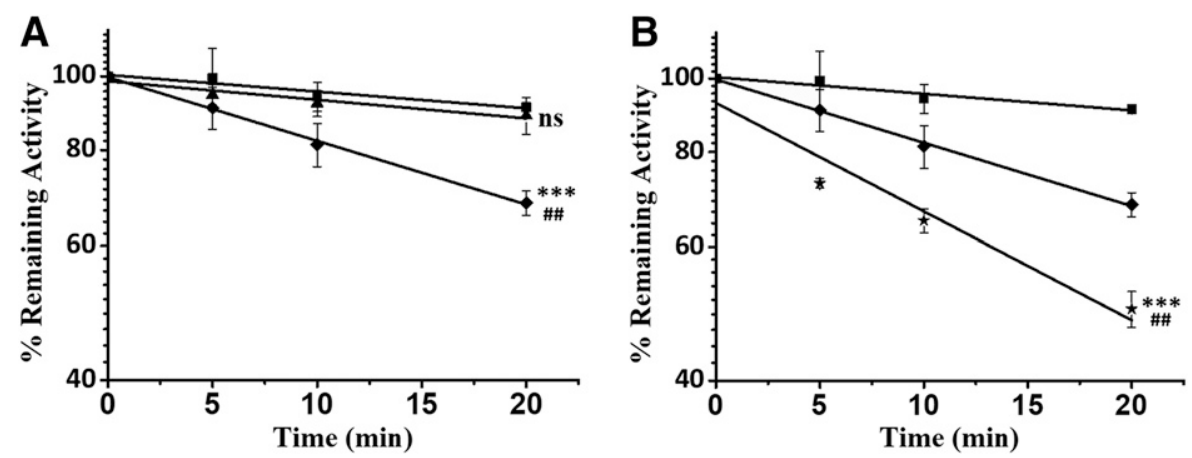

Fig. 6. (A) Time- and NADPH-dependent inhibition of CYP3A by DM-PPR $(80 \mu \mathrm{M})$. Human liver microsomes $(0.5 \mathrm{mg}$ protein $/ \mathrm{ml})$ were incubated with vehicle $(\boldsymbol{\bullet})$, or DM-PPR $(80 \mu \mathrm{M})$ in the absence $(\boldsymbol{\Lambda})$ or presence $(\checkmark)$ of $\mathrm{NADPH}$ at $37^{\circ} \mathrm{C}$ for $0,5,10$, and 20 minutes. (B) Human liver microsomes $(0.5 \mathrm{mg}$ protein/ $\mathrm{ml})$ were incubated with vehicle (๘), DM-PPR $(80 \mu \mathrm{M})$ $(\star)$, or PPR $(80 \mu \mathrm{M})(\star)$ in the presence of NADPH. The residual enzymatic activities at 0 minute were normalized to $100 \%$. Data represent the mean \pm S.D. $(n=3) . *$ indicates the significance of the remaining enzyme activity of experimental groups with respect to that of control at the same time point (20 minute) of incubations. (A) \# indicates the significance of the remaining activity in the presence of NADPH, compared with that in the absence of NADPH under the same incubation condition; (B) \# indicates the significance of the remaining activity of the incubation containing DM-PPR $(80 \mu \mathrm{M})$, compared with that of PPR $(80 \mu \mathrm{M})$ in the presence of NADPH under the same conditions. ${ }^{\# \#} P<0.01$; and $* * * P<0.001$ are considered significantly different; ns, not significant. human liver microsomes in the presence of individual selective CYP inhibitors. Similar microsomal incubations as described above were conducted with the minor modification that CYP inhibitors were included in microsomal mixtures besides the components listed above. The inhibitors applied, along with their final concentrations, were $\alpha$-naphthoflavone (10 $\mu \mathrm{M}$ for 1A2), methoxsalen (20 $\mu \mathrm{M}$ for 2A6), sulfaphenazole (20 $\mu \mathrm{M}$ for $2 \mathrm{C} 9$ ), ticlopidine (100 $\mu \mathrm{M}$ for $2 \mathrm{~B} 6$ and $2 \mathrm{C} 19)$, quinidine (10 $\mu \mathrm{M}$ for $2 \mathrm{D} 6)$, disulfiram (10 $\mu \mathrm{M}$ for $2 \mathrm{E} 1)$, and ketoconazole (10 $\mu \mathrm{M}$ for $3 \mathrm{~A}$ ) (referring to the FDA Guidance for Industry on Drug Interaction Studies). The control group did not include the inhibitors. Sample preparation and product quantification were performed as above. $\mathrm{P} 450$ activities were calculated as the percentage of the control activities, each incubation was carried out three times in three separate days.

Recombinant Human P450 Incubations. Similar incubations were conducted as above microsomal study, and PPR was incubated with individual recombinant human $\mathrm{P} 450$ enzymes (100 $\mathrm{nM}$ in each incubation), including CYPs2A6, 2C9, 1A2, 2E1, 3A4, 2C19, 3A5, 2B6, and 2D6, in place of human liver microsomes. The resulting NAC adducts (M3-M8) were analyzed and quantified by LC-MS/MS. The formation of NAC adducts (\%) was calculated by determination of the ratio of peak area of metabolites in individual recombinant CYP enzymes to the most abundance of the metabolites generated.

Statistical Analysis. All of the data reported represent the mean \pm S.D. Statistical evaluation was performed using unpaired $t$ test, and $* P<0.05$, ${ }^{* *} P<$ 0.01 , and $* * * P<0.001$ were accepted to be statistically significant.

\section{Results}

Overview of PPR-Mediated Time-Dependent Inhibition of P450 Enzymes. In order to define the inhibitory effect of PPR $(80 \mu \mathrm{M})$ on

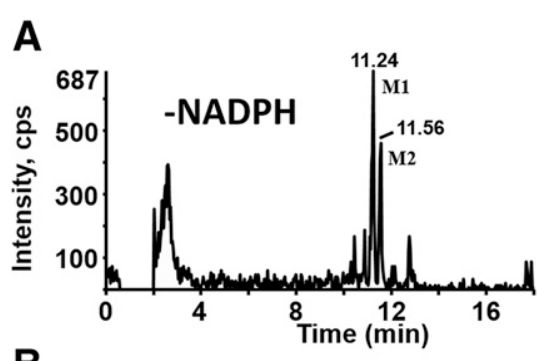

B

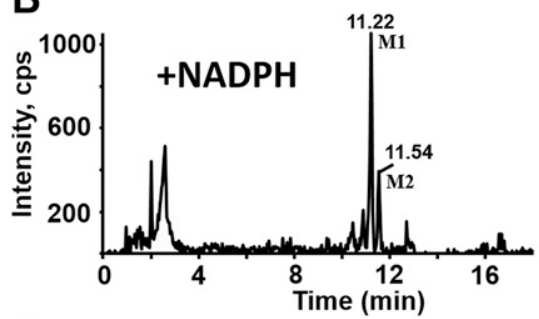

C

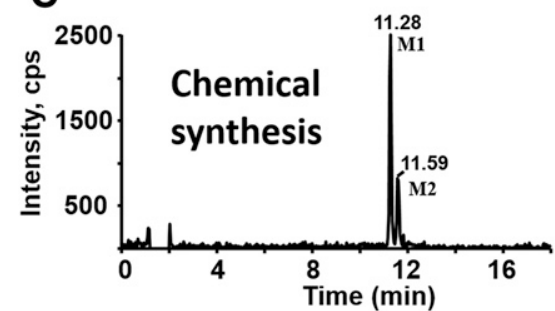

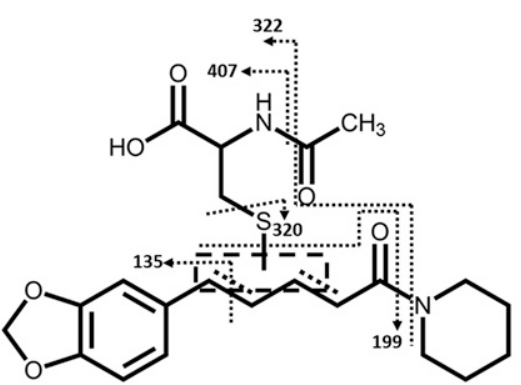

D

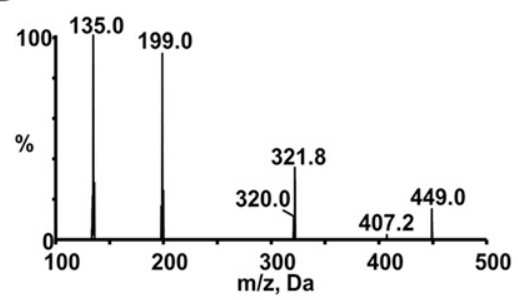

E

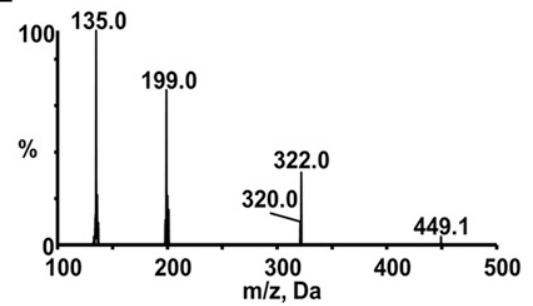

Fig. 7. MS characterization of metabolites $\mathrm{M} 1$ and $\mathrm{M} 2$. Extracted ion $(\mathrm{m} / \mathrm{z}$ 449.0/320.0 for M1 and M2) chromatograms obtained from LC-MS/MS analysis of incubations containing PPR, human liver microsomes, and NAC in the absence (A) or presence of NADPH (B). (C) Extracted ion chromatograms obtained from LC-MS/MS analysis of synthetic M1 and M2. (D) MS/MS spectra of M1 and M2 generated in microsomal incubations. (E) MS/MS spectra of synthetic M1 and M2. 
seven common CYP enzymes, we first performed a quick screening study. The remaining activities of the seven CYP enzymes were measured after incubation at various time points. As illustrated in Fig. 1, loss of CYPs3A and 2D6 activities was observed after 20 minutes incubation. The remaining enzyme activities of CYP3A and CYP2D6 were about $50 \%$ and $57 \%$, respectively.

Time-, Concentration-, and NADPH-Dependent Inhibition of CYP3A by PPR. As shown in Fig. 2A, CYP3A activity decreased with incubation time after exposure to PPR at concentrations of 5.0, 10, 20, 40,60 , or $80 \mu \mathrm{M}$. Specifically, exposure to PPR at $80 \mu \mathrm{M}$ in 20 minutes at $37^{\circ} \mathrm{C}$ resulted in a loss of approximately $50 \%$ CYP3A activity (Fig. 2A). No such enzyme inactivation was observed in the absence of either PPR or NADPH (Fig. 2B) under the same incubation condition.

A double-reciprocal plot (Wilson's plot) of the observed rates of inactivation $\left(k_{\mathrm{obs}}\right)$ and PPR concentrations above were applied to calculate kinetic constants $K_{\mathrm{I}}$ and $k_{\text {inact }}$ (Fig. 2C). $K_{\mathrm{I}}$ was obtained from the negative reciprocal of the $x$-axis intercept, and $k_{\text {inact }}$ was determined by the value of the 2.3/y-axis intercept (Alvarez-Diez and Zheng, 2004). Therefore, $K_{\mathrm{I}}$ and $k_{\text {inact }}$ were calculated to be $30.7 \mu \mathrm{M}$ and 0.041 minutes $^{-1}$, respectively.

Protection Effect of Competitive Inhibitor on PPR-Mediated CYP3A Inactivation. Ketoconazole was coincubated with PPR in human liver microsomes. The protective effect of ketoconazole increased with the increase in concentrations of ketoconazole applied (Fig. 3). The residual enzymatic activity of CYP3A in the absence of ketoconazole was $47.9 \% \pm 5.2 \%$ at 20 minutes, while the remaining enzyme activities were $59.3 \% \pm 0.7 \%, 71.6 \% \pm 1.9 \%$, and $81.0 \% \pm 1.3 \%$ in the presence of ketoconazole at concentrations of $0.01,0.1$, and $1.0 \mu \mathrm{M}$, respectively.

Effects of GSH and SOD/Catalase on Enzyme Inactivation. The effects of GSH and SOD/catalase on enzyme inactivation were determined by examining PPR-mediated CYP3A inactivation in the absence or presence of GSH as well as SOD/catalase. After incubation for 20 minutes, the remaining activities of CYP3A were $55.1 \% \pm$ $1.1 \%$ with GSH $(2.0 \mathrm{mM})$ and $52.5 \% \pm 0.7 \%$ without GSH. SOD and catalase, scavengers of reactive oxygen species (ROS), displayed little protective effects on the inactivation of CYP3A, and the remaining enzyme activities were $53.0 \% \pm 3.5 \%$ (with $\mathrm{SOD} /$ catalase) and $52.5 \% \pm 0.7 \%$ (without SOD/catalase) after 20 minute incubations.

Partition Ratio for Inactivation of CYP3A4 by PPR. Partition ratio ( $P$ value) is a measure of the efficiency of a mechanism-based inactivator. The $P$ value was calculated by a plot of the remaining enzyme activity versus the PPR/CYP3A4 molar ratio. As shown in Fig. 4, two linear regression lines were seen, with PPR/CYP3A4 as the abscissa and the remaining enzyme activity as the ordinate. The $P$ value was 273 calculated from $P+1$ of 274 estimated based on the value of the intersection of two linear regression lines.

Reversibility of Inactivation. The dialysis experiment was designed and executed to determine the reversibility of the observed CYP3A enzyme inhibition after exposure to PPR. The changes in CYP3A activity of microsomes exposed to PPR and those treated with vehicle before and after dialysis were examined. Apparently, the observed loss of CYP3A activity was reversed by 6 hours dialysis, and the enzyme activity was restored from $28.2 \% \pm 3.2 \%$ (predialysis) to $71.9 \% \pm$ $5.2 \%$ (post-dialysis), about $43.7 \%$ of CYP3A activity was recovered.

Effect of Ferricyanide on PPR-Mediated CYP3A Inhibition. The contribution of carbene intermediate to enzyme inactivation was investigated by selective oxidation of carbene-iron complex with potassium ferricyanide. Compared with the vehicle group, $39.7 \%$ of CYP3A activity was recovered when PPR-pretreated $(80 \mu \mathrm{M})$ microsomes were incubated with $\mathrm{K}_{3} \mathrm{Fe}(\mathrm{CN})_{6}(2.0 \mathrm{mM})$ (Table 1$)$.

Formation of Quinone Metabolite from PPR. Characterization of reactive metabolites of PPR was carried out in human liver microsomes
A
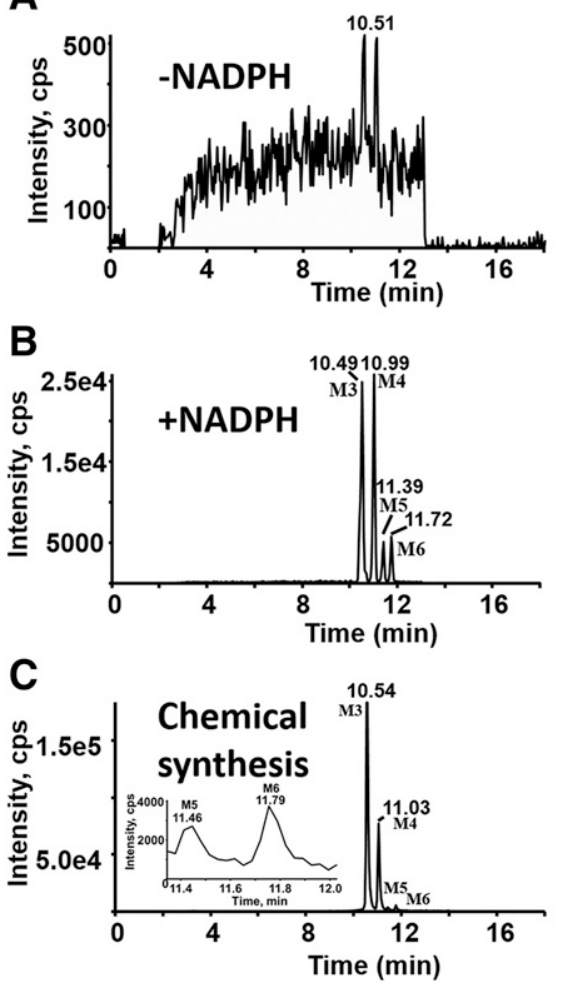

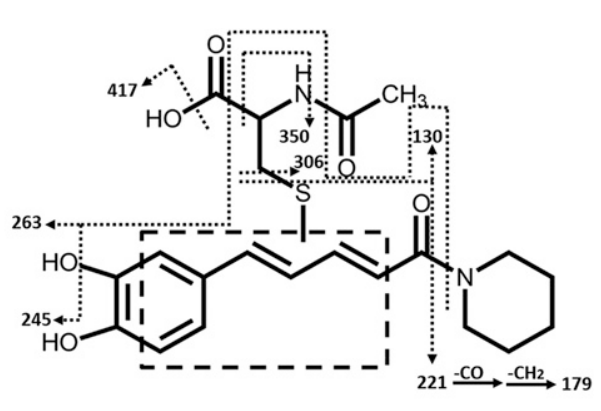

D

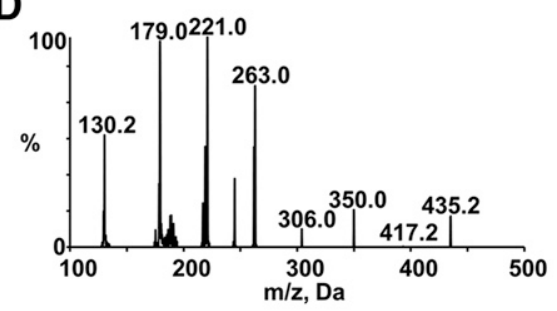

E

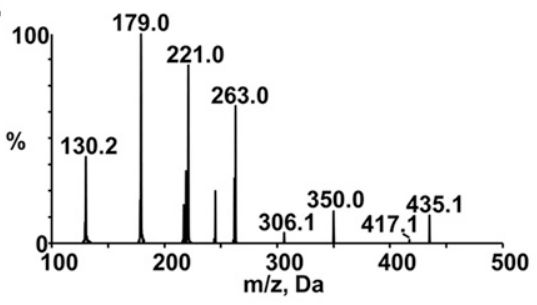

Fig. 8. MS characterization of DM-PPR-derived NAC conjugates M3-M6. Extracted ion $(\mathrm{m} / \mathrm{z}$ 435.0/221.0 for M3-M6) chromatograms obtained from LC-MS/MS analysis of incubations containing PPR, human liver microsomes, and NAC in the absence (A) or presence of NADPH (B). (C) Extracted ion chromatograms obtained from LC-MS/MS analysis of synthetic M3-M6. (D) MS/MS spectra of M3-M6 generated in microsomal incubations. (E) MS/MS spectra of synthetic M3-M6. 
supplemented with NAC as a trapping agent. A total of eight NAC conjugates (M1-M8) were found in the resulting microsomal mixture. Metabolites M1 and M2 with $[\mathrm{M}+\mathrm{H}]^{+}$ion at $\mathrm{m} / \mathrm{z} 449$ eluted at 11.22 and 11.54 minutes, respectively (Fig. 7B). And their mass spectra showed representative fragment ions related to the NAC moiety (Fig. 7D). The product ion at $m / z, 320$ was obtained from the neutral cleavage of the $\mathrm{C}-\mathrm{S}$ bond of the NAC moiety $(-129 \mathrm{Da})$. The fragment ion at $m / z 407$ originated from the loss of the acetyl portion $(-42 \mathrm{Da})$ from $\mathrm{m} / \mathrm{z} 449$. Product ion at $\mathrm{m} / \mathrm{z} 322$ arose from the loss of the piperidine ring ( $-85 \mathrm{Da}$ ) from $\mathrm{m} / \mathrm{z}, 407$. The fragment ion at $\mathrm{m} / \mathrm{z}, 135$ resulted from the cleavage of PPR portion. In addition, M1 and M2 were detected in microsomal incubations both in the absence and presence of NADPH (Fig. 7, A and B).Fig 5

Another two types of NAC adducts with molecular ions $m / z 435$ (M3M6) and 437 (M7, M8) were detected (Fig. 8B; Fig. 9B, respectively; Schemes 1 and 2). Four peaks assigned as M3 (retention time $=10.49$ minutes), M4 (retention time $=10.99$ minutes), M5 (retention time $=$ 11.39 minutes), and M6 (retention time $=11.72$ minutes) (Fig. $8 \mathrm{~B}$ ) showed their $[\mathrm{M}+\mathrm{H}]^{+}$at $m / z 435$, in agreement with the molecular weight of DM-PPR-derived NAC conjugates. The generation of M3-M6 was NADPH-dependent (Fig. 8, A and B). MRM-EPI of ion transition at $m / z, 435 / 221$ was scanned to acquire the MS/MS spectra of the four NAC conjugates. Identification of M3-M6 was based on the major fragments at $\mathrm{m} / \mathrm{z}$ 306, 263, and 221 (Fig. 8D). Fragment ion $\mathrm{m} / \mathrm{z}$ 306 came from the characteristic neutral loss of 129 Da (the NAC moiety) from $\mathrm{m} / \mathrm{z}$ 435, and fragment ion $\mathrm{m} / \mathrm{z} 221$ was derived from the loss of piperidine ring $(-85 \mathrm{Da})$ from $\mathrm{m} / \mathrm{z} 306$. The product ion at $\mathrm{m} / \mathrm{z}$ 263 resulted from the loss of the acetyl, carboxyl, and piperidine ring of the parent ion.Fig 5
In addition to M3-M6, another type of DM-PPR-derived NAC conjugates, namely, M7 and M8, with retention time at 10.99 and 11.37 minutes (Fig. 9B) were detected in the above microsomal incubations. Incubations in the absence of NADPH did not produce the two conjugates (Fig. 9A). The molecular ion of conjugates M7-M8 was $m / z 437$, which is $2 \mathrm{Da}(2 \mathrm{H})$ higher than that of M3-M6 $(\mathrm{m} / z, 435)$. MRM-EPI scanning (ion transition $m / z$ 437/181) revealed representative fragment ions (Fig. 9D), including $m / z, 308$ (loss of $129 \mathrm{Da}$ ) associated with the indicative neutral loss of the NAC portion, $\mathrm{m} / \mathrm{z}, 223$ derived from the further loss of piperidine ring ( $-85 \mathrm{Da}$ ) from $\mathrm{m} / \mathrm{z}, 308$, and $\mathrm{m} / \mathrm{z}, 181$ generated from the loss of $-\mathrm{CO}(28 \mathrm{Da})$ and $-\mathrm{CH}_{2}(14 \mathrm{Da})$ of $\mathrm{m} / z 223$.

Chemical synthesis was carried out to verify the structure of the metabolites detected in microsomal incubations. M1-M8 were all observed in the synthetic mixture by LC-MS/MS. The resulting products showed the same chromatographic (Fig. 7C, Fig. 8C, Fig. 9C) and mass spectrometric (Fig. 7E; Fig. 8E; Fig. 9E) identities as those generated in microsomal incubations. Unfortunately, poor reaction yield and heavy impurity with similar retention time mad us fail to obtain sufficient amounts of the individual products for NMR characterization.

Time- and NADPH-Dependent Inhibition of CYP3A by DM-PPR. To probe further probe the contribution of carbene intermediate to the inhibition of CYP3A, DM-PPR was synthesized and tested. High-resolution mass spectrometry analysis of synthetic DMPPR revealed its $[\mathrm{M}+\mathrm{H}]^{+}$of $m / z$ 274.1436, consistent with the corresponding theoretical mass within 5 ppm, compared with the predicted formula (Supplemental Table 1). We succeeded in obtaining ${ }^{1} \mathrm{H}$ NMR (DMSO- $d_{6}, 600 \mathrm{MHz}$ ) spectrum of synthetic DM-PPR (Supplemental Fig. 1), and the proton assignment is listed in Fig. 5. The signals responsible for the methylene moiety observed in the ${ }^{1} \mathrm{H}$
A

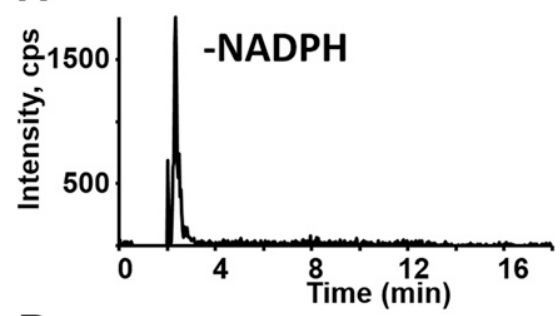

B
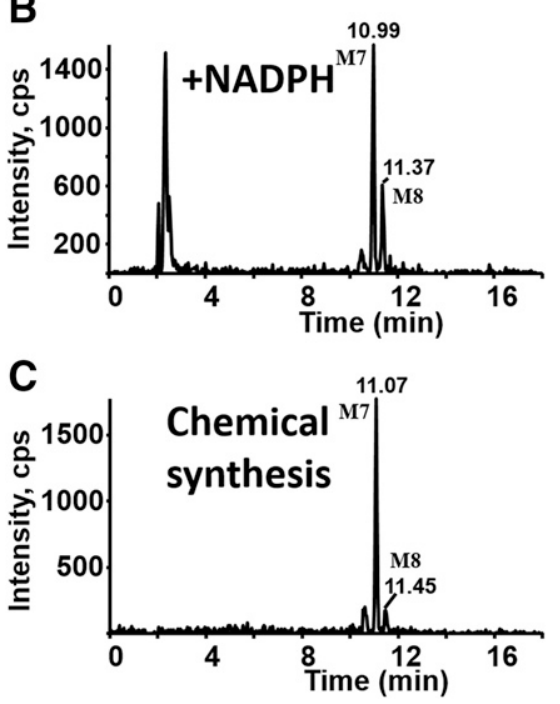

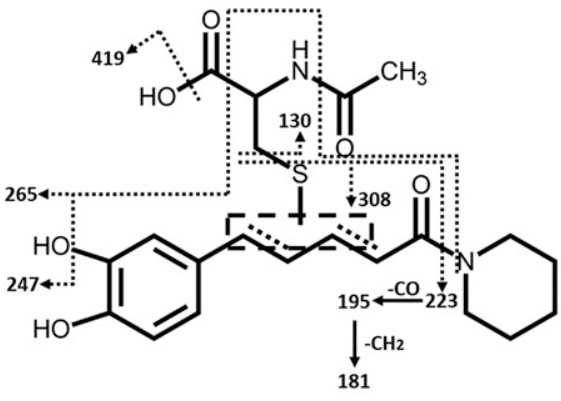

D

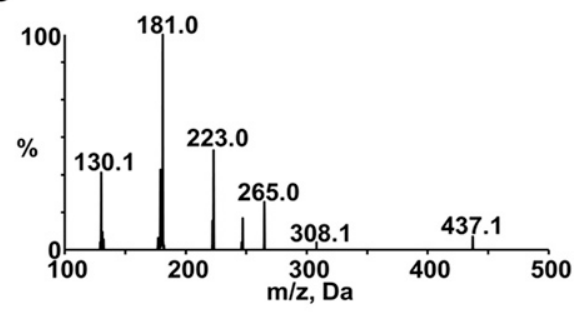

E

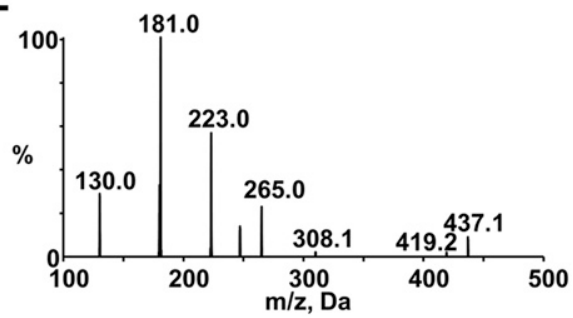

Fig. 9. MS characterization of DM-PPR-derived NAC conjugates M7 and M8. Extracted ion $(\mathrm{m} / \mathrm{z} 437.0 / 181.0$ for M7 and M8) chromatograms obtained from LC-MS/ MS analysis of incubations containing PPR, human liver microsomes, and NAC in the absence (A) or presence of NADPH (B). (C) Extracted ion chromatograms obtained from LC-MS/MS analysis of synthetic M7 and M8. (D) MS/MS spectra of M7 and M8 generated in microsomal incubations. (E) MS/MS spectra of synthetic M7 and M8. 
<smiles>CC(=O)NC(C[SH+]CC1CCCC(O)C1=O)C(=O)O</smiles><smiles>CC(=O)NC(CS[C@]1(O)C(=O)C(O)=CC=C1/C=C/C=C/C(=O)N1CCCCC1)C(=O)O</smiles><smiles>CC(=O)NC(CSCC=CC1=CC(=O)C(=O)C=C1)C(=O)N1CCC(C)CC1</smiles>

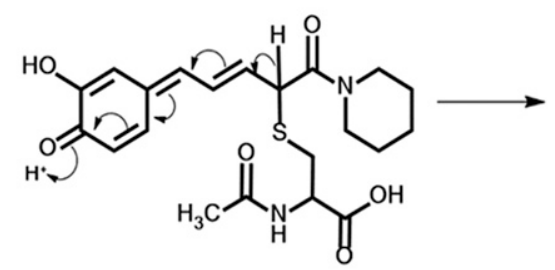<smiles>CC(=O)NC(CS/C(=C\C=C\c1ccc(O)c(O)c1)C(=O)N1CCCCC1)C(=O)O</smiles>

M3-M6<smiles>CC(=O)NC(C[CH-]c1ccc(O)c(O)c1)C(=O)O</smiles><smiles>CC(=O)NC(CSC(/C=C/C=C/C(=O)N1CCCCC1)c1ccc(O)c(O)c1)C(=O)O</smiles><smiles>CC(=O)NC(CSC(C/C=C/C(=O)N1CCCCC1)c1ccc(O)c(O)c1)C(=O)O</smiles>

M7, M8

Scheme 2. Proposed mechanisms for the formation of NAC conjugates M3-M8.

NMR spectrum of the parent compound disappeared in the spectrum of the product.

DM-PPR at concentrations of 0 and $80 \mu \mathrm{M}$, was incubated with human liver microsomes in the absence or presence of NADPH and displayed time-dependent inhibition of CYP3A. NADPH was required for enzyme inhibition (Fig. 6A). Exposure to DM-PPR at $80 \mu \mathrm{M}$ for 20 minutes at $37^{\circ} \mathrm{C}$ resulted in about a $31.8 \% \pm 2.5 \%$ loss of CYP3A activity (Fig. 6), while exposure to the parent compound at the same molar concentration resulted in a $50.3 \% \pm 2.7 \%$ loss (Fig. 6B) of enzyme activity under the same condition.

P450 Enzymes Responsible for PPR Bioactivation. To identify which P450 enzymes are mainly responsible for the bioactivation of PPR, nine human recombinant CYPs were individually incubated with PPR, NAC, and NADPH, followed by assessment of the formation of M3-M6 and M7, M8. P450 1A2 was the major enzyme participating in the formation of M3-M6 and M7, M8 (Fig. 10A; Fig. 11A).

Additionally, PPR was incubated with human liver microsomes fortified with NAC in the absence or presence of individual P450 enzyme inhibitors. As shown in Figs. 10B and 11B, $\alpha$-naphthoflavone, inhibitor of CYP 1A2, elicited inhibitory effects on the production of M3-M6 and M7, M8. Specifically, the production of M3-M6 and M7, M8 remained at levels of $55.2 \% \pm 1.6 \%, 54.0 \% \pm 3.9 \%, 68.6 \% \pm$ $4.9 \%, 72.0 \% \pm 5.8 \%, 53.5 \% \pm 6.5 \%$, and $72.0 \% \pm 3.6 \%$, respectively.

\section{Discussion}

The rapid screening experiment demonstrated that PPR caused significant loss of CYP3A and CYP2D6 activity after 20 minutes of microsomal incubation (Fig. 1). Apparently, PPR inhibited CYP3A the most, which encouraged us to investigate the interaction of PPR with CYP3A as a model enzyme.
PPR was found to cause time-, concentration-, and NADPHdependent inhibition of CYP3A (Fig. 2, A and B). The observed requirement of NADPH for PPR-mediated CYP3A inhibition indicates that metabolic activation was involved in the enzyme inhibition. Competitive inhibitor coincubation experiments showed that ketoconazole reduced the enzyme inactivation of CYP3A by PPR (Fig. 3). This result suggests that the bioactivation of PPR occurred at the active site of CYP3A, and the competitive binding of ketoconazole in the active site of the host enzyme protected the enzyme from inactivation (MorunoDavila et al., 2001).

In consideration of reactive intermediates that release from the active site of the host enzyme and of ROS produced during metabolism also can contribute to enzyme inactivation, the effects of GSH and scavengers of ROS on enzyme inactivation were determined. GSH revealed minor protection against enzyme inactivation by PPR. This indicates that the reactive intermediates produced via $\mathrm{P} 450$-mediated metabolism resided the pocket of the host enzyme. SOD and catalase, scavengers of ROS, displayed little protective effect on the inactivation of CYP3A, That implies that ROS, if produced, was not involved in the enzyme inactivation.

Partition ratio $(P$ value $)$ is a measure to evaluate the effectiveness of a mechanism-based inactivator. The less the value is, the more effective the inactivator. The reported $P$ values of mechanism-based inactivators ranged from almost zero to several thousands (Kent et al., 2001). The observed $P$ value of PPR was approximately 273 (Fig. 4), which can be classified as a moderately efficient inactivator of CYP3A4.

Dialysis experiments were conducted to define the interaction of the metabolite of PPR with host enzyme CYP3A. Apparently, dialysis restored the enzyme activity of CYP3A, indicating that the binding mode of the enzyme to the metabolite was noncovalent. 


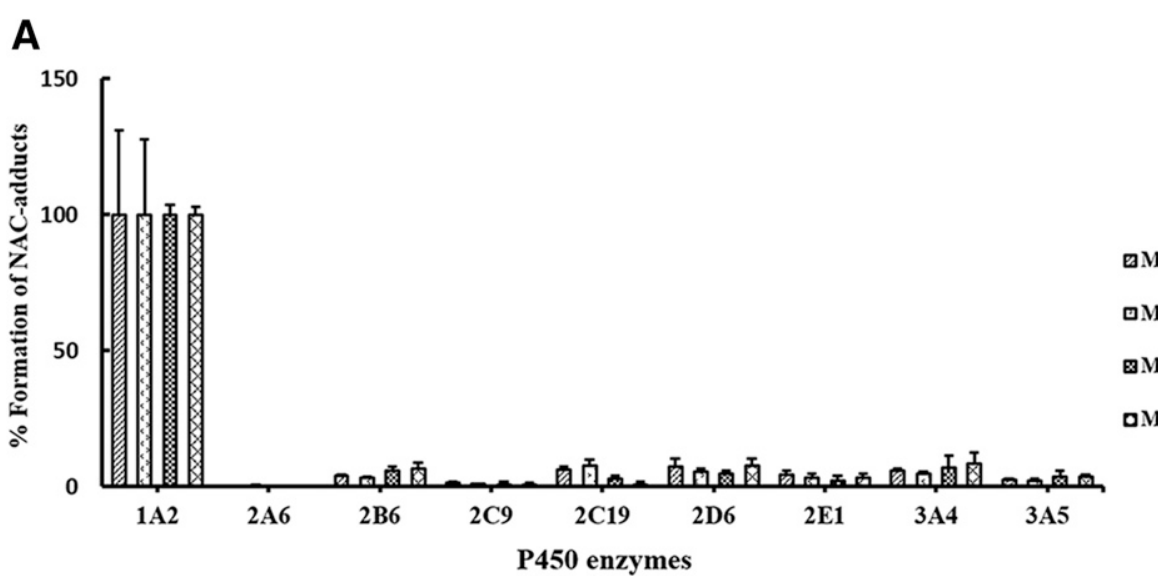

B

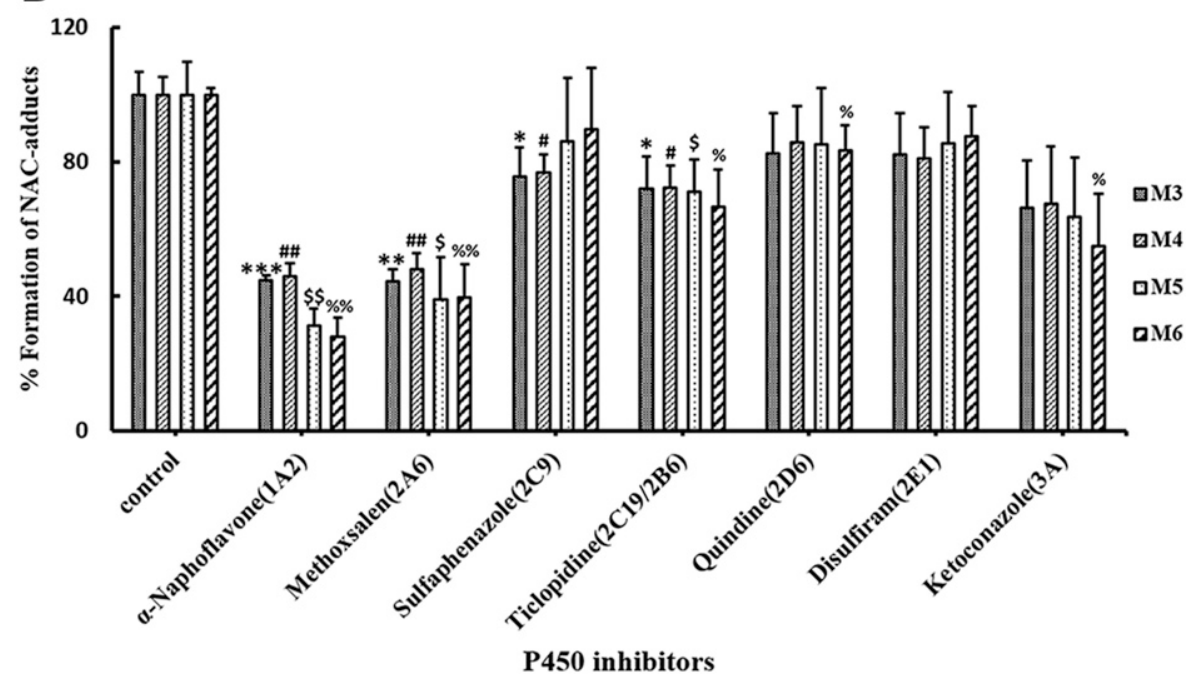

Fig. 10. P450 enzymes responsible for the generation of M3-M6 in vitro. (A) Rates of M3-M6 formation in incubations containing PPR, individual recombinant P450 enzymes, NAC, and NADPH. (B) Effects of selective P450 inhibitors on the generation of M3-M6. PPR was incubated with human liver microsomes, NAC, and NADPH, in the absence (control) or presence of individual P450 enzyme inhibitors. Data represent the mean \pm S.D. $\left(n=3^{2}{ }^{*}, \#, \$\right.$, and $\%$ indicate the significance of the amount of M3-M6 produced in experimental groups compared with that of the control, respectively. Comparisons were made using unpaired $t$ test. ${ }^{* / \# / \$ / \%} P<0.05 ;{ }^{*} *^{/ \# \# / \$ \$ / \% \%} P<0.01$; $* * * / \# \# \# \$ \$ \$ \% \% \% P<0.001$ are considered significantly different.
MDP compounds can be metabolized to carbene intermediates mediated by $\mathrm{P} 450$ enzymes, and the resulting carbene may coordinate with the iron of the heme, resulting in inhibition of the host enzymes (Buening and Franklin, 1976; Muakkassah et al., 1982). Potassium ferricyanide can reportedly reverse the carbene-mediated inhibition by selective oxidation and dissociation of carbene-heme-iron-porphyrin complexes (Buening and Franklin, 1976). The addition of $\mathrm{K}_{3} \mathrm{Fe}(\mathrm{CN})_{6}$ showed a protective effect on the inhibition of CYP3A by PPR in the incubation (Table 1), indicating that the formation of the carbene-iron complex was possibly involved in CYP3A inactivation.

Alternatively, the resulting carbene may be converted to the corresponding formate ester, The formate ester may be hydrolyzed to catechol and further oxidized to the corresponding ortho-quinone (Scheme 1) (Murray, 2000). As expected, we succeeded in detection the NAC conjugate derived from the putative quinone intermediate in human liver microsomal incubations (Fig. 8; Scheme 2). In addition, NAC conjugates M3-M8 were detected in human liver microsomal incubations with synthetic DM-PPR (Supplemental Fig. 3, A and B). This suggests $\mathrm{P} 450$-mediated formation of the quinone intermediate proposed in Scheme 1. To determine the contribution of the quinone intermediate in PPR-mediated CYP3A inactivation, we evaluated the inhibitory effect of DM-PPR and found that DM-PPR showed weak enzyme inactivation relative to that caused by PPR (Fig. 6). Whether the enzyme inhibition by DM-PPR is reversible was determined by dialysis. As expected, exhaustive dialysis failed to restore the DM-PPR inhibited CYP3A activity (the residual CYP3A activities were $46.7 \% \pm 7.4 \%$ without dialysis and $52.8 \% \pm 3.9 \%$ with dialysis). Taken together, the observed CYP3A inactivation resulted not only from carbene-mediated iron coordination but also from quinone-derived protein modification.

Structurally, PPR is a Michael acceptor (unsaturated ketone). As expected, two NAC conjugates (M1 and M2) were detected in human liver microsomal incubations, possibly resulting from 1,4- to 1,6addition (Scheme 1). Additionally, cysteine conjugates were observed in PPR-exposed recombinant CYP3A4 after proteolytic digestion (Supplemental Fig. 2). Thus, we cannot exclude the possibility that the observed enzyme inactivation arose from nonspecific covalent modification of CYP3A via the Michael addition. This prompted us to determine the potential involvement of the nonspecific modification in the enzyme inactivation. As a result, we failed to see enzyme inactivation in the absence of NADPH. This suggests that the nonspecific protein addition, if it took place, did not necessarily cause enzyme inactivation.

Both recombinant and microsomal inhibition studies verified that CYP1A2 was the primary enzyme participating in the bioactivation of PPR measured by monitoring the formation of NAC adducts derived from the quinone intermediate (M3-M8) (Figs. 10 and 11). Methoxsalen was reportedly an inhibitor of both CYPs 2A6 and 1A2 (Ono et al., 1996). That is probably why the results obtained from the CYP2A6 recombinant incubations and microsomal inhibition incubations did not quite match each other. Interestingly, CYP1A2 was found to be the major enzyme which mediated the bioactivation of PPR, but PPR caused significant inactivation of CYP3A and slight inactivation of CYP2D6. Reactive metabolites generated in the active site of CYP3A selectively 
A

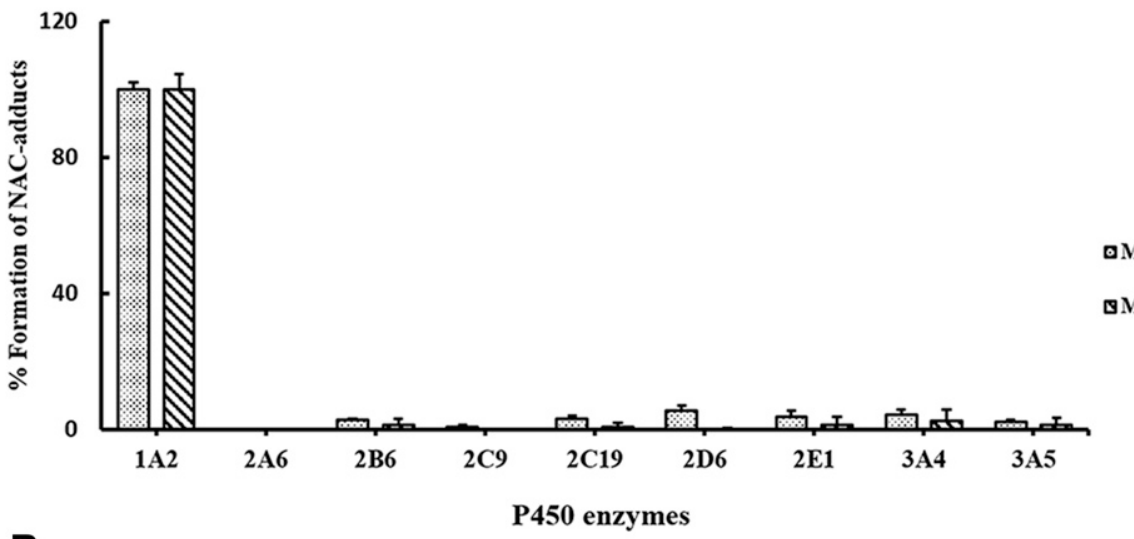

Fig. 11. $\mathrm{P} 450$ enzymes responsible for the generation of M7 and M8 in vitro. (A) Rates of M7 and M8 formation in incubations containing PPR, individual recombinant P450 enzymes, NAC, and NADPH. (B) Effects of selective P450 inhibitors on the generation of M7 and M8. PPR was incubated with human liver microsomes, NAC, and NADPH in the absence (control) or presence of individual P450 enzyme inhibitors. Data represent the mean \pm S.D. $(n=3)$. * and ${ }^{\#}$ indicate the significance of the amount of M7 and M8 produced in experimental groups, compared with that of the control, respectively. Comparisons were made using unpaired $t$ test. ${ }^{* / \#} P<0.05 ; * * P<0.01$

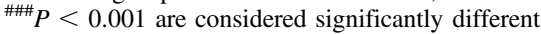

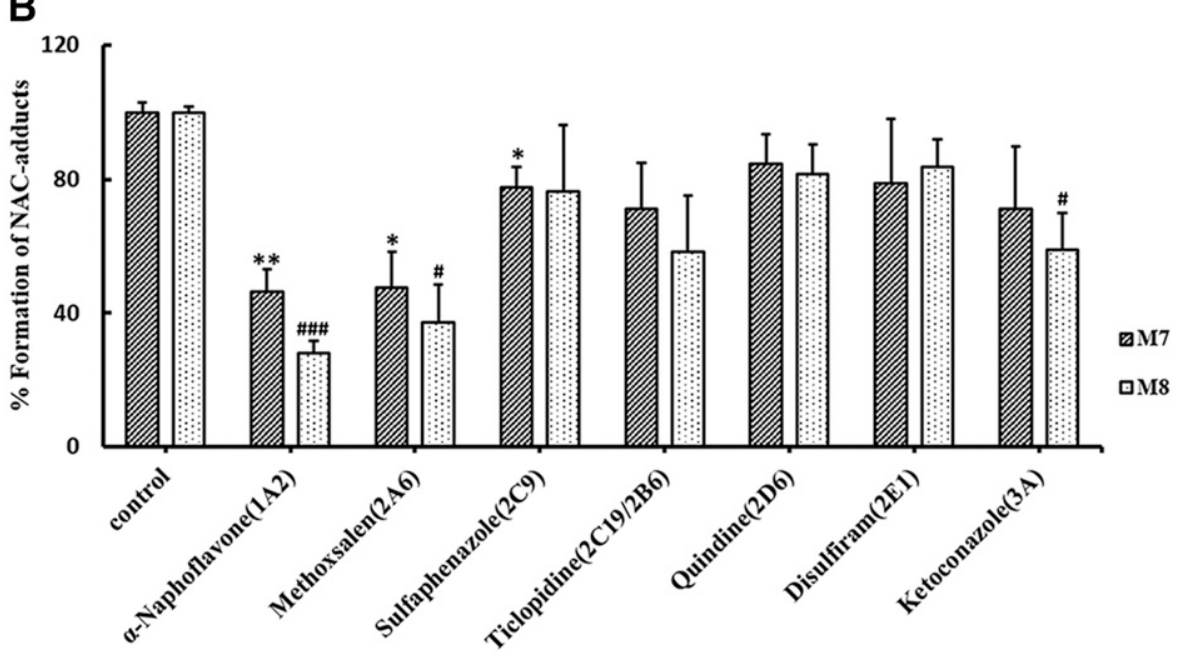

P450 inhibitors

inactivated the host enzymes, which made their activity not surviving long enough to produce many metabolites. Additionally, reactive metabolites generated in the active site of enzymes did not necessarily result in inactivating the host enzymes, and it also depends on the availability of nucleophilic amino acid residues at their active sites and the suitable distance between the resulting reactive intermediate and the targeting nucleophilic amino acid residues of the host enzymes. For some reason, the reactive metabolite generated in situ was unable to modify the amino acid residue(s) in the active site of CYP1A2, sequentially escaped from the host enzymes, and trapped by NAC. Whether PPR is a mechanism-based inactivator of CYP2D6 needs further investigation.

In summary, PPR quasi-irreversibly inhibited CYP3A, and biotransformation was required for the enzyme inactivation. Both the carbene and ortho-quinone reactive intermediates are involved in the inactivation of CYP3A.

\section{Authorship Contributions \\ Participated in research design: Cui, Peng, Zheng. \\ Conducted experiments: Cui, Wang, Tian, Zhang. \\ Performed data analysis: Cui. \\ Wrote or contributed to the writing of the manuscript: Cui, Zheng.}

\section{References}

Alvarez-Diez TM and Zheng J (2004) Mechanism-based inactivation of cytochrome P450 3A4 by 4-ipomeanol. Chem Res Toxicol 17:150-157.
Bae GS, Kim MS, Jung WS, Seo SW, Yun SW, Kim SG, Park RK, Kim EC, Song HJ, and Park SJ (2010) Inhibition of lipopolysaccharide-induced inflammatory responses by piperine. Eur $J$ Pharmacol 642:154-162.

Bang JS, Oh DH, Choi HM, Sur BJ, Lim SJ, Kim JY, Yang HI, Yoo MC, Hahm DH, and Kim KS (2009) Anti-inflammatory and antiarthritic effects of piperine in human interleukin $1 \beta$-stimulated fibroblast-like synoviocytes and in rat arthritis models. Arthritis Res Ther 11:R49.

Buening MK and Franklin MR (1976) SKF 525-A inhibition, induction, and 452-nm complex formation. Drug Metab Dispos 4:244-255.

Bukhari IA, Pivac N, Alhumayyd MS, Mahesar AL, and Gilani AH (2013) The analgesic and anticonvulsant effects of piperine in mice. J Physiol Pharmacol 64:789-794.

Casida JE (1970) Mixed-function oxidase involvement in the biochemistry of insecticide synergists. $J$ Agric Food Chem 18:753-772.

Chonpathompikunlert P, Wattanathorn J, and Muchimapura S (2010) Piperine, the main alkaloid of Thai black pepper, protects against neurodegeneration and cognitive impairment in animal model of cognitive deficit like condition of Alzheimer's disease. Food Chem Toxicol 48:798-802.

Gong FY, Cui LF, Zhang XN, Zhan XB, Gong X, and Wen Y (2017) Piperine ameliorates collagenase-induced Achilles tendon injury in the rat. Connect Tissue Res 59 (6):21-29.

Gupta RA, Motiwala MN, Dumore NG, Danao KR, and Ganjare AB (2015) Effect of piperine on inhibition of FFA induced TLR4 mediated inflammation and amelioration of acetic acid induced ulcerative colitis in mice. J Ethnopharmacol 164:239-246.

Hong Y, Chia YMF, Yeo RH, Venkatesan G, Koh SK, Chai CLL, Zhou L, Kojodjojo P, and Chan ECY (2015) Inactivation of human cytochrome P450 3A4 and 3A5 by dronedarone and N-desbutyl dronedarone. Mol Pharmacol 89:1-13.

Hutzler JM, Melton RJ, Rumsey JM, Schnute ME, Locuson CW, and Wienkers LC (2006) Inhibition of cytochrome P450 3A4 by a pyrimidineimidazole: evidence for complex heme interactions. Chem Res Toxicol 19:1650-1659.

Hutzler JM, Melton RJ, Rumsey JM, Thompson DC, Rock DA, and Wienkers LC (2008) Assessment of the metabolism and intrinsic reactivity of a novel catechol metabolite. Chem Res Toxicol 21:1125-1133.

Johri RK and Zutshi U (1992) An Ayurvedic formulation 'Trikatu' and its constituents. J Ethnopharmacol 37:85-91.

Katiyar SS, Muntimadugu E, Rafeeqi TA, Domb AJ, and Khan W (2016) Co-delivery of rapamycin- and piperine-loaded polymeric nanoparticles for breast cancer treatment. Drug Deliv $\mathbf{2 3}$ 2608-2616.

Kent UM, Juschyshyn MI, and Hollenberg PF (2001) Mechanism-based inactivators as probes of cytochrome P450 structure and function. Curr Drug Metab 2:215-243. 
Kumar A, Khan IA, Koul S, Koul JL, Taneja SC, Ali I, Ali F, Sharma S, Mirza ZM, Kumar M, et al. (2008) Novel structural analogues of piperine as inhibitors of the NorA efflux pump of Staphylococcus aureus. J Antimicrob Chemother 61:1270-1276.

Lee JY, Lee SY, Oh SJ, Lee KH, Jung YS, and Kim SK (2012) Assessment of drug-drug interactions caused by metabolism-dependent cytochrome P450 inhibition. Chem Biol Interact 198:49-56.

Lin JH and Lu AY (1998) Inhibition and induction of cytochrome P450 and the clinical implications. Clin Pharmacokinet 35:361-390.

Moruno-Dávila MA, Garrido-del Solo C, García-Moreno M, Havsteen BH, Garcia-Sevilla F, Garcia-Cánovas F, and Varón R (2001) Kinetic analysis of enzyme systems with suicide substrate in the presence of a reversible competitive inhibitor, tested by simulated progress curves. Int J Biochem Cell Biol 33:181-191.

Muakkassah SF, Bidlack WR, and Yang WC (1982) Reversal of the effects of isoniazid on hepatic cytochrome P-450 by potassium ferricyanide. Biochem Pharmacol 31:249-251.

Murray GI, Barnes TS, Sewell HF, Ewen SW, Melvin WT, and Burke MD (1988) The immunocytochemical localisation and distribution of cytochrome P-450 in normal human hepatic and extrahepatic tissues with a monoclonal antibody to human cytochrome P-450. Br J Clin Pharmacol 25:465-475.

Murray M (2000) Mechanisms of inhibitory and regulatory effects of methylenedioxyphenyl compounds on cytochrome P450-dependent drug oxidation. Curr Drug Metab 1:67-84.

Murunikkara V, Pragasam SJ, Kodandaraman G, Sabina EP, and Rasool M (2012) Antiinflammatory effect of piperine in adjuvant-induced arthritic rats--a biochemical approach. In flammation 35:1348-1356.

Ohnishi A, Matsuo H, Yamada S, Takanaga H, Morimoto S, Shoyama Y, Ohtani H, and Sawada Y (2000) Effect of furanocoumarin derivatives in grapefruit juice on the uptake of vinblastine by Caco-2 cells and on the activity of cytochrome P450 3A4. Br J Pharmacol 130:1369-1377.

Ono S, Hatanaka T, Hotta H, Satoh T, Gonzalez FJ, and Tsutsui M (1996) Specificity of substrate and inhibitor probes for cytochrome P450s: evaluation of in vitro metabolism using cDNAexpressed human P450s and human liver microsomes. Xenobiotica 26:681-693.

Parkinson A, Kazmi F, Buckley DB, Yerino P, Paris BL, Holsapple J, Toren P, Otradovec SM, and Ogilvie BW (2011) An evaluation of the dilution method for identifying metabolismdependent inhibitors of cytochrome P450 enzymes. Drug Metab Dispos 39:1370-1387.

Rama Subba Rao V, Suresh G, Ranga Rao R, Suresh Babu K. Chashoo G, Saxena A, and Madhusudana Rao J (2012) Synthesis of piperine-amino acid ester conjugates and study of their cytotoxic activities against human cancer cell lines. Med Chem Res 21:38-46.

Rendic S and Di Carlo FJ (1997) Human cytochrome P450 enzymes: a status report summarizing their reactions, substrates, inducers, and inhibitors. Drug Metab Rev 29:413-580.

Salminen KA, Meyer A, Imming P, and Raunio H (2011) CYP2C19 progress curve analysis and mechanism-based inactivation by three methylenedioxyphenyl compounds. Drug Metab Dispos 39:2283-2289.

Samra YA, Said HS, Elsherbiny NM, Liou GI, El-Shishtawy MM, and Eissa LA (2016) Cepharanthine and Piperine ameliorate diabetic nephropathy in rats: role of NF- $\mathrm{KB}$ and NLRP3 inflammasome. Life Sci 157:187-199.
Tasleem F, Azhar I, Ali SN, Perveen S, and Mahmood ZA (2014) Analgesic and anti-inflammatory activities of Piper nigrum L. Asian Pac J Trop Med 7S1:S461-S468.

Taxak N, Patel B, and Bharatam PV (2013) Carbene generation by cytochromes and electronic structure of heme-iron-porphyrin-carbene complex: a quantum chemical study. Inorg Chem $\mathbf{5 2}$ 5097-5109.

Umadevi P, Deepti K, and Venugopal DVR (2013) Synthesis, anticancer and antibacterial activities of piperine analogs. Med Chem Res 22:5466-5471.

Umar S, Golam Sarwar AH, Umar K, Ahmad N, Sajad M, Ahmad S, Katiyar CK, and Khan HA (2013) Piperine ameliorates oxidative stress, inflammation and histological outcome in collagen induced arthritis. Cell Immunol 284:51-59.

Usia T, Watabe T, Kadota S, and Tezuka Y (2005) Metabolite-cytochrome P450 complex formation by methylenedioxyphenyl lignans of Piper cubeba: mechanism-based inhibition. Life Sci 76:2381-2391.

VandenBrink BM and Isoherranen N (2010) The role of metabolites in predicting drug-drug interactions: focus on irreversible cytochrome P450 inhibition. Curr Opin Drug Discov Devel 13:66-77.

Wangensteen H, Molden E, Christensen H, and Malterud KE (2003) Identification of epoxybergamottin as a CYP3A4 inhibitor in grapefruit peel. Eur J Clin Pharmacol 58:663-668

Watanabe A, Nakamura K, Okudaira N, Okazaki O, and Sudo K (2007) Risk assessment for drugdrug interaction caused by metabolism-based inhibition of CYP3A using automated in vitro assay systems and its application in the early drug discovery process. Drug Metab Dispos 35: $1232-1238$.

Wattanathorn J, Chonpathompikunlert P, Muchimapura S, Priprem A, and Tankamnerdthai O (2008) Piperine, the potential functional food for mood and cognitive disorders. Food Chem Toxicol 46:3106-3110.

Yang AH, He X, Chen JX, He LN, Jin CH, Wang LL, Zhang FL, and An LJ (2015) Identification and characterization of reactive metabolites in myristicin-mediated mechanism-based inhibition of CYP1A2. Chem Biol Interact 237:133-140.

Zarai Z, Boujelbene E, Ben Salem N, Gargouri Y, and Sayari A (2013) Antioxidant and antimicrobial activities of various solvent extracts, piperine and piperic acid from Piper nigrum. Lebensm Wiss Technol 50:634-641.

Address correspondence to: Dr. Jiang Zheng, State Key Laboratory of Functions and Applications of Medicinal Plants, Key Laboratory of Pharmaceutics of Guizhou Province, Guizhou Medical University, Guiyang, Guizhou, 550004, P. R. China; Wuya College of Innovation, Shenyang Pharmaceutical University, Shenyang, P. R. China. E-mail: zhengneu@yahoo.com; or Dr. Ying Peng, Wuya College of Innovation, Shenyang Pharmaceutical University, Shenyang, Liaoning, 110016, P. R. China. E-mail: yingpeng1999@163.com 